\title{
Dynamic Debt Deleveraging and Optimal Monetary Policy*
}

\author{
Pierpaolo Benigno \\ LUISS and EIEF
}

\author{
Gauti B. Eggertsson \\ Brown University and NBER
}

\author{
Federica Romei \\ European University Institute
}

September 2014

\begin{abstract}
This paper studies optimal monetary policy under dynamic debt deleveraging once the zero bound is binding. Unlike the existing literature, the natural rate of interest is endogenous and depends on macroeconomic policy. Optimal monetary policy successfully raises the natural rate of interest by creating an environment that speeds up deleveraging, thus endogenously shortening the duration of the crisis and a binding zero bound. Inflation should be front loaded. Fiscalpolicy multipliers can be even higher than in existing models, but depend on the way in which public spending is financed.

Key words: Monetary policy, zero lower bound, debt deleveraging JEL: E31, E32, E52

*We are grateful to conference participants at the Federal Reserve Bank of Cleveland, the Midwest Macro Meetings, the EEA-ESEM 2014 conference, and to the internal seminar partecipants at Wirtschaftsuniversität Wien. We also thank Nicolas Cuche-Curti, Alexander Mechanick and Sanjay Singh for comments and Alyson Price for editorial as-
\end{abstract} sistance. 


\section{Introduction}

There is a relatively large literature on monetary and fiscal policy subject to the zero interest rate bound (see for example Eggertsson and Woodford (2003), Adam and Billi (2006), Eggertsson (2011), Christiano, Eichenbaum and Rebelo (2011) and Werning (2011)). Generally, these papers take the shock that leads the economy to the zero bound - shocks to the "natural rate of interest" - as given. Hence the duration of the trap under some basic policy specifications is purely exogenous and the duration of the exogenous forces that perturb the economy - usually given by preference shocks - does not have much meaningful interaction with the policy chosen.

More recently a literature has started to emerge that tries to model in greater detail how the economy finds itself up against the zero bound, the very origin of the current global economic crisis. One powerful narrative is that the source is a deleveraging cycle (for recent theoretical contributions inspired by the crisis see e.g. Eggertsson and Krugman (2012), Hall (2012) and Guerreri and Lorenzoni (2012), while Mian and Sufi (2011) provide empirical evidence for this mechanism). ${ }^{1}$

The deleveraging story can be summarized as follows: We first have a period of too much optimism about debt, in which debtors borrow and spend aggressively via a process of leveraging (piling up debt). Since one person's debt is another's asset, creditors have to be induced to spend less via high real interest rates. Then there is a "Minsky moment" (Eggertsson and Krugman, 2012) in which people realize things have gone too far - that all the newly issued debt may in fact not be sustainable - and we move from a process of leveraging to deleveraging, i.e. the overextended agents need to pay down their debt. But the problem is that this process is not symmetric, because the central bank may not be able to cut the interest rate enough to induce sufficient spending by those that are not too deep into debt because of the zero bound. Hence, one way to explain a drop in the natural rate of interest is to say that debtors - as a group - are trying to deleverage very fast, so that the real interest rate needs to fall to negative levels to get the savers to spend enough to sustain full employment. A negative real interest rate can make the zero bound binding. This in turns creates problems for macroeconomic

\footnotetext{
${ }^{1}$ See also Geanakoplos (2010), and references therein, altough he, and the literature cited, does not emphasize the connection of the levereage cycle to the interest rate channel as we do here and as the literature above does. Thus he does not focus as much on the interaction of the leverage cycle and the zero bound which is the central focus here.
} 
policy.

In earlier work on deleveraging, such as Eggertsson and Krugman (2012), the deleveraging shock corresponds to a sudden drop in borrowing capacity that the borrower must satisfy. Left off the table, however, is the precise dynamic path and time horizon of the deleveraging. Instead the deleveraging all takes place in one period termed the "short-run". In this paper we relax this assumption so that the process of deleveraging takes place over several periods - determined endogenously - as a result of the optimal deleveraging decisions of the optimizing households. To do so we model in more detail the form of the borrowing capacity of the households, which we assume is not an exogenous constant as in Eggertsson and Krugman (2012). ${ }^{2}$ Instead it is a convex function of each agent's level of debt. Under this specification the debtor is not at a corner (i.e. at the very edge of his debt limit) but instead chooses his optimal level of debt, taking into account that higher level of debt will trigger an ever higher "risky" interest rate for him to face.

Within this framework we generalize the standard New Keynesian (NK) prototype model (such as for example illustrated in Woodford (2003) and Galì (2008)) as one that involves exactly the same pair of equations, familiar to many readers, namely the IS and the AS equations which are typically summarized as follows (denoting output in log deviation from steady state with, $\hat{Y}_{t}$, inflation with $\pi_{t}$, the nominal interest rate with $i_{t}$ )

$$
\begin{gathered}
\hat{Y}_{t}=E_{t} \hat{Y}_{t+1}-\sigma\left(i_{t}-E_{t} \pi_{t+1}-r_{t}^{n}\right) \\
\pi_{t}=\kappa \hat{Y}_{t}+\beta \pi_{t+1}
\end{gathered}
$$

where $\beta, \sigma, \kappa>0$ are coefficients. The only difference between our current model and the standard system is that $r_{t}^{n}$ (which has the interpretation of being the natural rate of interest) is now an endogenous variable that depends on the level of outstanding private debt. In the paper we will show how this variable is now determined in equilibrium by a system of equations that depends on the households' level of indebtedness, among other things. Our deleveraging shock corresponds to a "shock" to the "safe level" of debt, giving the household an incentive to pay down their debt to a new lower level that is determined in equilibrium. In this transition period we show that the natural rate of interest can be temporarily negative.

\footnotetext{
${ }^{2}$ Our formulation is closer to one of their suggested extensions building on Curdia and Woodford (2010), with some important differences outlined in the text.
} 
The first main conclusion of the paper is that the duration of a negative natural rate of interest is now endogenous - rather than depending only on exogenous preference shocks or an implicitly specified "short-run" - and is dependent on the stance of policy. Under a monetary policy regime that targets high enough inflation (or employ an aggressive enough fiscal policy) to avoid the zero bound, for example, the economy will experience a shorter duration of a negative natural rate of interest than if the policy regime is insufficiently stimulating. The intuition for this is straightforward: In a recession there is a drop in overall income, hurting borrowers' ability to pay down their debt, which means that the process of deleveraging will be slower than if the recession is avoided via aggressive enough monetary and fiscal policy. Since it is the deleveraging process that drives the reduction in the natural rate of interest, this affects how long the natural rate of interest stays below its steady state.

The second key result of the paper is to some extent a corollary of the first. Endogenous deleveraging will in general amplify the effect of policy at the zero bound. Why? Policy will now not only dampen the crisis today, as the previous literature has emphasized, but also shorten its duration by directly affecting the natural rate of interest. Consider the nominal interest rate path under a policy that tries to stabilize inflation, and the output gap assuming either dynamic deleveraging or exogenous preference shocks. We find that optimal monetary policy under dynamic deleveraging prescribes a shorter duration at the zero bound than if the crisis was driven by exogenous preference shocks, precisely because it will have a direct effect on the natural rate of interest: Optimal policy is powerful enough to "jump start" the economy and thus lead to a more rapid normalization of the nominal interest rate than would otherwise have occurred.

Our third result is that we are able to explicitly derive a social welfare function inside our heterogenous agent model. While the standard New Keynesian model involves only output and inflation, the social welfare function in our model involves an additional term because of the imperfect risk-sharing of the agents in our model. Relative to the standard objective, we find that this additional term gives the government even further reason to engage in countercyclical policy and dampen the effect of the recession on output and prices.

A fourth result that emerges is that we find that optimal monetary policy in a liquidity trap under dynamic deleveraging will prescribe excess inflation, and possibly output above potential, well above the inflation target, even 
during the period in which the zero bound is binding and the natural rate of interest is negative. This is mostly explained by the added stabilization objective that our model prescribes for the policymaker, but also to some (albeit lesser) extent due to the fact that an endogenous natural rate of interest prescribes even more aggressive policy action than in the standard model.

Finally, we study the effects of fiscal policy under dynamic deleveraging. There we find that it can be even more effective than has been found in the previous literature, since a fiscal expansion speeds up the deleveraging cycle. Crucially, the effectiveness of policy depends on how it is financed.

This work is organized as follows. Section 2 first describes dynamic deleveraging in a simple endowment economy to clarify some key assumptions. It then presents the general model. Section 3 discusses the log-linear version of the general model. Section 4 studies debt deleveraging without taking into account the zero lower bound under a simple inflation-targeting policy replicating the flexible-price allocation. Section 5 adds to the previous case the zero lower bound. Section 6 compares inflation-targeting policies between the standard NK model, where movements of the natural rate of interest are exogenous, and the deleveraging model of this paper, where the natural rate of interest is endogenous. Section 7 studies optimal monetary policy under commitment and compares the result with the standard NK model. Section 8 investigates fiscal-policy multipliers and finally Section 9 concludes.

\section{Model}

\subsection{Dynamic deleveraging in an endowment economy}

We start out by showing a simple example of dynamic deleveraging in an endowment economy. This is helpful to clarify the role of some key assumptions in the general environment we propose in the next subsection. Imagine a closed-economy endowment model with two agents, a borrower and a saver. They have the following utility functions

$$
E_{t} \sum_{T=t}^{\infty}\left(\beta^{j}\right)^{T-t} \log C_{t}^{j} \quad \text { where } j=b \text { or } s
$$


in which $C_{t}^{j}$ is consumption of agent $j$ and $0<\beta^{j}<1$ is the discount factor, with $\beta^{s} \geq \beta^{b}$. They make their consumption choices subject to a standard budget constraint

$$
\frac{b_{t}^{j}}{1+r_{t}^{j}}=b_{t-1}^{j}+C_{t}^{j}-\frac{1}{2} Y+T_{t}^{j}
$$

where $b_{t}^{j}$ is one-period risk-free real debt of agent $j$ and $r_{t}^{j}$ is the associated interest rate and $Y$ is the endowment that remains constant. We adopt the notation that $b_{t-1}^{j}$ is the amount repaid in period $t$ in terms of the consumption good of the debt contracted in period $t-1$ (inclusive of interest payments). Hence the real value in terms of the consumption good of the debt contracted in period $t$ is $b_{t}^{j} /\left(1+r_{t}^{j}\right)$. We also adopt the notation that a positive number for $b_{t}^{j}$ denotes debt, while a negative one an asset. $T_{t}^{j}$ is a lump-sum transfer out of the control of the agent.

Let us define the risk-free real interest rate by $1+r_{t}$. We now consider the following function for the interest rate faced by each agent $j$

$$
\begin{array}{llr}
1+r_{t}^{j}=1+r_{t} & \text { if } & b_{t}^{j} \leq \bar{b}_{t} \\
1+r_{t}^{j}=\left(1+r_{t}\right)\left\{1+\phi\left(b_{t}^{j}-\bar{b}_{t}\right)\right\} & \text { if } & b_{t}^{j}>\bar{b}_{t}
\end{array}
$$

This relationship says that as long as the debt the agent has contracted is below some threshold $\bar{b}_{t}$ he can borrow at the risk-free interest rate. If debt is higher than the threshold, however, the agent faces an interest rate that is different from the risk-free rate and given by the linear relationship in equation (2) where $\phi$ is a positive parameter. This relationship, shown in Figure 1, says that if the borrower's debt level is below $\bar{b}_{t}$ then he faces the risk-free rate $1+r_{t}$. If he borrows above $\bar{b}_{t}$, however, he needs to pay a premium above the risk-free rate given by $1+\phi\left(b_{t}^{b}-\bar{b}_{t}\right)$. Hence as the borrowing increases, so does the rate the borrower needs to pay. This can be thought of as a generalization of the strict borrowing-limit in Eggertsson and Krugman (2012) where $b_{t} \leq \bar{b}_{t}$. That constraint is obtained in the limit as $\phi \rightarrow \infty$ since in that case the borrower will never exceed the borrowing limit; while in our case the borrower may choose to do so but at the expenses of paying some premium over the risk-free rate.

Given the simple structure outlined above an equilibrium in the model is a collection of stochastic processes $\left\{C_{t}^{b}, C_{t}^{s}, r_{t}^{b}, r_{t}^{s}, b_{t}^{b}\right\}$ that satisfies the following 
five equations

$$
\begin{gathered}
\frac{1}{C_{t}^{s}}=\beta^{s}\left(1+r_{t}^{s}\right) E_{t} \frac{1}{C_{t+1}^{s}} \\
\frac{1}{C_{t}^{b}}=\beta^{s}\left(1+r_{t}^{b}\right) E_{t} \frac{1}{C_{t+1}^{b}} \\
1+r_{t}^{b}=\left(1+r_{t}^{s}\right)\left(1+\phi\left(b_{t}^{b}-\bar{b}_{t}\right)\right) \quad \text { if } b_{t}^{b} \geq \bar{b}_{t} \\
1+r_{t}^{b}=\left(1+r_{t}^{s}\right) \quad \text { if } b_{t}^{b}<\bar{b}_{t} \\
C_{t}^{s}+C_{t}^{b}=Y \quad \\
b_{t}^{b}=\left(1+r_{t}^{b}\right)\left[b_{t-1}^{b}+C_{t}^{b}-\frac{1}{2} Y\right]
\end{gathered}
$$

where the first two equations are the consumption Euler equations of the saver and the borrower respectively. The third equation determines the spread between the rate faced by the borrower and the lender; it follows directly from (1) and (2). The fourth equation is the resource constraint and finally the last equation is the budget constraint of the borrower. Some details on how we arrive at these equations are in the footnote. ${ }^{3}$

It should be apparent from the equations above that the steady state of the model is relatively straightforward to derive. In particular we see from the first two equations that the real interest rate faced by each of the agents is given by their respective discount factors, i.e., $1+r^{s}=\left(\beta^{s}\right)^{-1}$ and $1+r^{b}=\left(\beta^{b}\right)^{-1}$. This, then, is enough to pin down the steady-state equilibrium debt given by equation (5) so that

$$
b^{b}=\bar{b}+\phi^{-1}\left(\frac{\beta^{s}}{\beta^{b}}-1\right)
$$

which is shown with $b_{s s}^{b}$ in Figure 1. The steady state debt just derived suggests that the borrower will borrow above the threshold $\bar{b}$ to an extent so that the borrowing rate $r^{b}$ equals the borrower's discount rate. Notice

\footnotetext{
${ }^{3}$ The first order conditions are derived via writing up a Lagrangian. Here we make the simplifying assumption that the borrower takes $b_{t}^{b}$ in the interest-rate premium function as exogenous (corresponding to aggregate debt in the economy). In the general model we allow the spread function to depend upon both individual and aggregate debt. We also make the assumption that the spread between the two interest rates is rebated lump sum to the saver which is why no lump sum transfer appears in (6). In the general model we put a little more structure on this by creating notation for banks, and assuming that the banks are owned by the savers.
} 


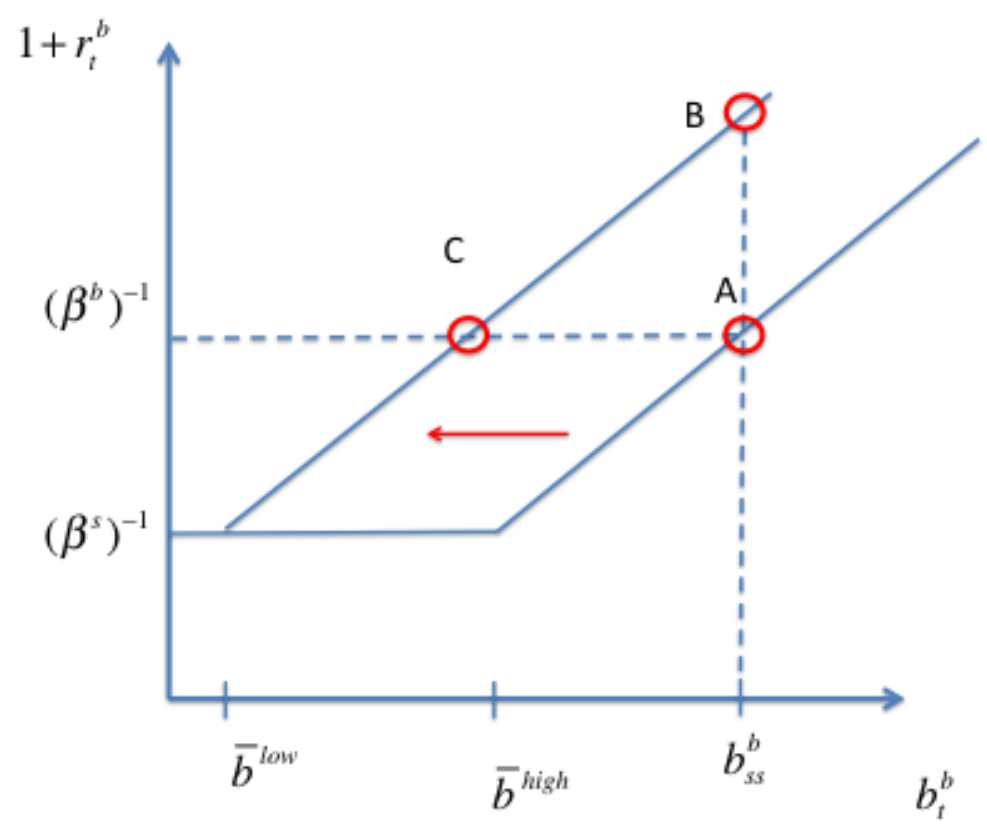

Figure 1: Plot of the function characterizing the cost of borrowing: equations (1) and (2) when $\bar{b}=\bar{b}^{\text {high }}$ and when $\bar{b}=\bar{b}^{\text {low }}$ with $\bar{b}^{\text {high }}>\bar{b}^{\text {low }}$. The initial steady state is $A$ when $\bar{b}=\bar{b}^{h i g h}$. As $\bar{b}$ moves to $\bar{b}^{\text {low }}$, the equilibrium moves to $B$ and then to the final steady state $C$ along the shifted line.

the contrast to Eggertsson and Krugman (2012), which can be obtained as a special case when $\phi \rightarrow \infty$ and the debt limit is binding so that $b^{b}=\bar{b}$ and the borrower is at a corner solution.

The key thought experiment we want to consider is the case when the debt limit $\bar{b}$ goes from some "high" level to a "low" one, i.e. $\bar{b}^{\text {high }} \rightarrow \bar{b}^{\text {low }}$, an experiment sometimes referred to as a Minsky moment. This thought experiment is shown in Figure 1. In the previous literature, such as Eggertsson and Krugman (2012), then by assumption the household pays down their debt immediately. Here, however, the borrower is no longer at a corner, instead, he is satisfying the consumption Euler equation (4). In the absence of any deleveraging, the borrower is faced with a higher borrowing cost than before, as shown in point B in Figure 1. The higher borrowing cost, however, gives the borrower the incentive to pay down his debt over time, to deleverage. The 
optimal dynamic path of deleveraging - which is in sharp contrast to the immediate deleveraging in Eggertsson and Krugman (2012) - can be explicitly derived by solving the dynamic equations (3)-(7), the solution of which we turn to next. The dynamic deleveraging is what moves the borrower from point $\mathrm{B}$ down to point $\mathrm{C}$ in Figure 1 where once again he faces an interest rate that is equal to the inverse of his discount factor, $\left(\beta^{b}\right)^{-1}$.

Figure 2 shows the path of each of the endogenous variables for illustrative values of the parameters which will generally take the same form for a finite $\phi{ }^{4}$ The deleveraging is accomplished over a period of time, which is determined optimally by the borrower as seen in the third panel on the first column, where private debt to output falls from $120 \%$ to around $98 \%{ }^{5}$ The borrower does so by cutting consumption and gradually paying down his debt. What induces the borrower to deleverage is the rise in the interest rate he faces given by $r_{t}^{b}$ as shown in the second panel on the first column of Figure 2. Meanwhile, to make up for this drop in spending the saver needs to correspondingly increase his own spending (since all output is consumed). For this to happen we observe that while the borrower's interest rate rises, the saver's interest rate drops in order to induce the saver to make up for the decline in spending by the borrower. The interest rate faced by the saver may even reach negative levels for a large enough shock to $\bar{b}$. Since the saver's rate is the risk-free short-term interest rate, which will correspond to the nominal interest rate set by the central bank in a more general setting, this will have major implications for monetary policy as we will soon see.

A few comments are now appropriate. First, observe that since the speed of the deleveraging - as determined by how long the agent takes to reach their new level of steady-state debt - is optimally determined in this economy, it is perhaps not hard to imagine for the reader at this point that this speed may be affected by macroeconomic policy, an insight we will soon confirm once we introduce endogenous production and endogenous macroeconomic policy. Crucially this implies that the duration of negative real interest rate for a riskless asset will be endogenous, and this will be critical to many of our results. Second, note that there is nothing in our experiment that depends on the gap between $\beta^{b}$ and $\beta^{s}$ to be large, which is vividly shown in Figure

\footnotetext{
${ }^{4}$ Illustrative parameters assumed: $\phi=0.4, Y=1 / 4, \beta^{b}=0.9033, \beta^{s}=.09756$, $\bar{b}^{\text {high }}=1, \bar{b}^{\text {low }}=0.78$. The model is log-linearized around the steady state to generate the figures.

${ }^{5}$ It should be noted that the shock $\bar{b}$ with respect to output, $\bar{b}^{g d p}$, moves from $100 \%$ to $78 \%$.
} 

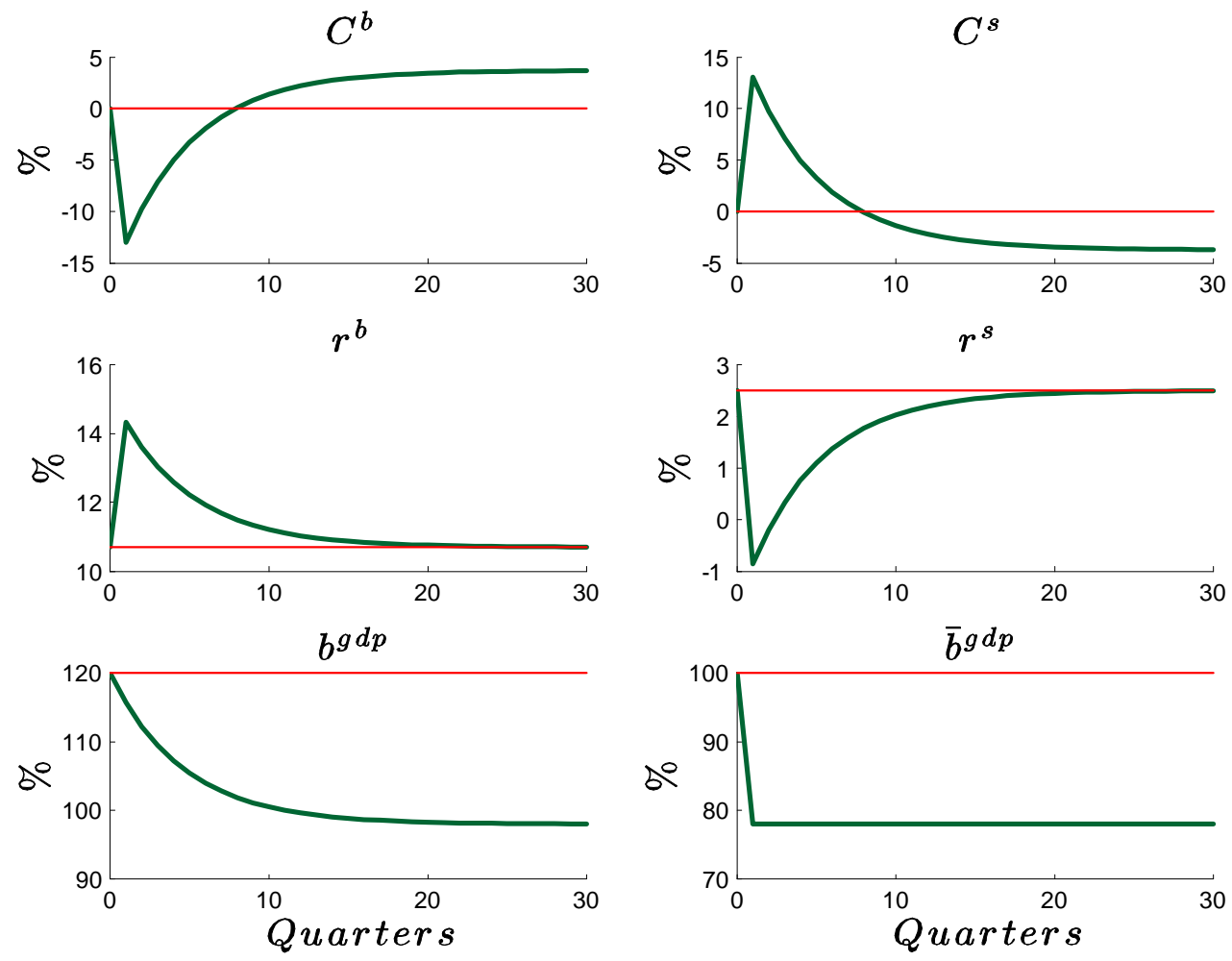

Figure 2: Responses following a deleveraging shock, $\bar{b}$ moves from $\bar{b}^{\text {high }}$ to $\bar{b}^{\text {low }}$, in the endowment-economy model. Variables are: consumption of borrowers $\left(C^{b}\right)$, consumption of savers $\left(C^{s}\right)$, real interest rate on borrowing $\left(r^{b}\right)$, real interest rate on saving $\left(r^{s}\right)$, debt of borrowers with respect to output $\left(b^{g d p}\right)$, the risk-free borrowing threshold with respect to output $\left(\bar{b}^{g d p}\right) . C^{b}, C^{s}$, are in percentage deviation with respect to the initial steady state; $r^{b}, r^{s}, b^{g d p}$ and $\bar{b}^{g d p}$ are in percent and at annual rates. 
1. Even if this gap is small, as long as $\bar{b}^{h i g h} \rightarrow \bar{b}^{\text {low }}$, then a spread will open to exactly the same extent and the borrower will deleverage. In other words, the dynamics of the deleveraging are independent of the difference between $\beta^{b}$ and $\beta^{s}$, only the steady state depends on this difference. In fact, even if $\beta^{b} \rightarrow \beta^{s}$ exactly the same thought experiment can be done as we have shown above. The reason this observation is important is that it is very convenient to assume that $\beta^{b} \rightarrow \beta^{s}$ for some (thought not all) aspects of our analysis. In particular, this assumption means that we can derive social welfare in a more tractable way as we will soon see. Accordingly, this will be the approach we will take in the next section. Note that in the case in which $\beta^{b} \rightarrow \beta^{s}$ borrowing and lending is no longer motivated by differences in discount factors. What defines borrowers and lenders in this case is the initial asset distribution, whereby some agents are born with debt, and others with assets. ${ }^{6}$

We will now extend this simple example, and again do a deleveraging experiment, into a more general setting. The main new elements of this environment relative to the simple example (apart from more general utility functions, monopolistic competition, general function for spreads and some banking microfoundations, etc) are that we will introduce endogenous production and explicitly model monetary and fiscal policy. Policy will have important effects because we assume that prices are set in advance in a staggered way.

Importantly we will see that the deleveraging shock of the type we have already seen will lead to major complications because of the zero bound on the short-term nominal interest rate. With a series of simplifying assumptions we will show that a model, such as the one shown in the example above, will naturally embed the standard prototype New Keynesian model. A key difference will be that the natural rate of interest - which is the very source of the zero bound problem - will now be endogenous and a function of the deleveraging process. It will thus be affected by policy. An important aspect of the model is that we are able to explicitly derive social welfare - which allows us to do optimal policy - a feature of the framework facilitated by the assumption that $\beta^{s} \rightarrow \beta^{b}$ as described above.

\footnotetext{
${ }^{6}$ In our example we can assume that the debtors have the debt $b^{b}=\bar{b}^{\text {high }}$. Observe that while there are initial conditions for debt consistent with lower values of the debt, it can be no higher than this value in steady state. Taking this initial value as given, then, and assuming a debt deleveraging shock, the new steady state will be uniquely defined as $b^{b}=\bar{b}^{\text {low }}$, precisely as in our exercise above.
} 


\subsection{General Environment}

Imagine now a closed economy lived in by a continuum of agents on a unitary interval. People are grouped into "savers", denoted by the subscript s, and "borrowers", denoted by the subscript b. There is a mass of measure $\chi$ of borrowers and $1-\chi$ of savers. Utility of a generic agent is given by

$$
E_{t} \sum_{T=t}^{\infty}\left(\beta^{j}\right)^{T-t}\left[U\left(C_{T}^{j}\right)-V\left(L_{T}^{j}\right)\right] \text { where } j=s \text { or } b
$$

in which $E_{t}$ denotes the standard expectation operator; $\beta^{j}$ is the intertemporal discount factor in preferences, with $0<\beta^{j}<1$, and $C$ is a consumption bundle

$$
C \equiv\left[\int_{0}^{1} C(i)^{\frac{\theta-1}{\theta}} d i\right]^{\frac{\theta}{\theta-1}}
$$

where $C(i)$ is the consumption of a generic good $i$ produced in the economy. There is a continuum of goods produced on the interval $[0,1] ; \theta$ is the intratemporal elasticity of substitution between goods with $\theta>1 ; L^{j}$ is hours worked.

Agents are subject to the following budget constraint

$$
\frac{B_{t}^{j}}{1+i_{t}^{j}}=B_{t-1}^{j}+P_{t} C_{t}^{j}-W_{t}^{j} L_{t}^{j}-\Psi_{t}^{j}-\Gamma_{t}^{j}+T_{t}^{j}
$$

where $B^{j}$, if positive, is nominal debt and conversely asset if negative. $P_{t}$ is the price index associated with the consumption bundle $C, W^{j}$ denotes wage specific to labor of quality $j ; \Psi^{j}$ are profits from operating firms which produce goods while $\Gamma_{t}^{j}$ are profits from financial intermediation; $T_{t}^{j}$ are lump-sum taxes.

The nominal interest rate $i_{t}^{j}$ is specific to the agent and we now specify a more general function for their interest-rate cost than in our simple example. Savers, which in equilibrium hold assets, will once again get the risk-free rate which we now specify in nominal term $i_{t}$. Instead borrowers, which in equilibrium are going to have debt, face a borrowing cost $^{7}$

$$
1+i_{t}^{j}=\left(1+i_{t}\right) \tilde{\phi}\left(\frac{b_{t}^{j}}{\bar{b}_{t}} ; \frac{b_{t}}{\bar{b}_{t}}\right)
$$

\footnotetext{
${ }^{7}$ This specification is a bit more general than the existing literature in that we allow the spread to depend both on individual debt and aggregate debt. This is important for the interpretation of the shocks in the model.
} 
which is proportional to the saving rate through a premium captured by the function $\tilde{\phi}(\cdot, \cdot)$. The borrowing premium depends on agent $j$ 's real debt, defined as $b_{t}^{j} \equiv B_{t}^{j} / P_{t}$, in reference to a level $\bar{b}_{t}$ which represents the maximum amount of real debt that can be considered risk-free at a certain point in time. The premium is also a function of the aggregate debt (per borrowers) given by $b_{t}=\left(\int_{\chi} b_{t}^{j} d j\right) / \chi$ again in reference with the same level $\bar{b}_{t}$. When the individual and aggregate debt levels are equal to $\bar{b}_{t}$, borrowing and saving rates coincide, this is similar to the inflection point in Figure 1. It is required that $\tilde{\phi}(1,1)=1$. Furthermore, we assume that it is always the case that $\tilde{\phi}(\cdot, \cdot) \geq 1$. The borrowing premium is also non-decreasing with the increasing borrowing of agent $j$, i.e. we assume that the derivative of the function with respect to the first argument is non-negative, $\tilde{\phi}_{b^{j}}(\cdot, \cdot) \geq 0$. Moreover, at the risk-free level $\bar{b}_{t}$, the marginal cost of increasing the individual borrowing capacity is zero, i.e. $\tilde{\phi}_{b^{j}}(1, \cdot)=0$, which is a sort of optimality condition at the individual level when borrowing is at the risk-free threshold. Finally, the borrowing premium is also non-decreasing with the increasing aggregate borrowing, meaning that the derivative of the function with respect to the second argument is non-negative $\tilde{\phi}_{b}(\cdot, \cdot) \geq 0 .{ }^{8}$

Because borrowers pay a higher interest rate than savers receive on their debt, there is profit from borrowing and lending. As in the simple example we assume this profit is rebated lump-sum to the savers. Let us put a little more structure on this by introducing some notation for financial intermediation. A positive spread implies each period that aggregate profits of intermediation are given by

$$
\Gamma_{t}=\int_{\chi}\left(\frac{1}{1+i_{t}}-\frac{1}{1+i_{t}^{j}}\right) b_{t}^{j} \geq 0 .
$$

The activity of intermediaries, or bank, is very simple in this model. They raise liquidity from the savers at the risk-free nominal interest rate $i_{t}$ to lend to borrowers at the higher interest rate $i_{t}^{j}$. The cost function (10) is then a technological constraint on the financial intermediation of the banks. We assume that the profits of banks are rebated only to the savers who own them. ${ }^{9}$

\footnotetext{
${ }^{8}$ We further assume that $\tilde{\phi}_{b}(1,1)>0$ and $\tilde{\phi}_{b^{i}, b}(1,1)+\tilde{\phi}_{b^{i}, b^{i}}(1,1)>0$ where $\tilde{\phi}_{b^{i}, b}(\cdot, \cdot)$ and $\tilde{\phi}_{b^{i}, b^{i}}(\cdot, \cdot)$ are cross derivatives.

${ }^{9}$ The quantitative, but not qualitative, results can change with alternative assumptions as explained later. It should be noted that $\Gamma_{t}^{j}$ in (9) are per-capita profits while $\Gamma_{t}$ are aggregate profits at time $t$.
} 
Households choose consumption and working hours to maximize utility (8) under the flow budget constraint (9) and an appropriate borrowing-limit condition. As outlined in Section 2.1 we now make the simplifying assumption that $\beta^{s} \rightarrow \beta^{b}=\beta$, in which case borrowing and lending are still well defined but determined by initial conditions.

The Euler's equation of savers implies

$$
U_{c}\left(C_{t}^{s}\right)=\beta\left(1+i_{t}\right) E_{t}\left\{U_{c}\left(C_{t+1}^{s}\right) \frac{P_{t}}{P_{t+1}}\right\} .
$$

Borrowers are not price takers with respect to the borrowing cost since they understand that it will be affected by their individual debt decision. For each individual $j$ belonging to the class of borrowers the following Euler equation can be derived:

$$
U_{c}\left(C_{t}^{j}\right)=\beta \frac{\left(1+i_{t}^{j}\right)}{1-\tilde{\epsilon}\left(\frac{b_{t}^{t}}{b_{t}}, \frac{b_{t}}{b_{t}}\right)} E_{t}\left\{U_{c}\left(C_{t+1}^{j}\right) \frac{P_{t}}{P_{t+1}}\right\},
$$

where the function $\tilde{\epsilon}(\cdot ; \cdot)$ captures the elasticity of the premium with respect to individual real debt and is defined by

$$
\tilde{\epsilon}\left(\frac{b_{t}^{j}}{\bar{b}_{t}} ; \frac{b_{t}}{\bar{b}_{t}}\right) \equiv \frac{b_{t}^{j}}{\bar{b}_{t}} \frac{\tilde{\phi}_{b^{j}}\left(\frac{b_{t}^{j}}{b_{t}} ; \frac{b_{t}}{b_{t}}\right)}{\tilde{\phi}\left(\frac{b_{t}^{j}}{b_{t}} ; \frac{b_{t}}{b_{t}}\right)} .
$$

In equilibrium, borrowers are identical and choose the same level of debt $b_{t}^{j}=b_{t}$. The Euler equation (12) can be simplified to

$$
U_{c}\left(C_{t}^{b}\right)=\beta \frac{\left(1+i_{t}^{b}\right)}{1-\epsilon\left(\frac{b_{t}}{b_{t}}\right)} E_{t}\left\{U_{c}\left(C_{t+1}^{b}\right) \frac{P_{t}}{P_{t+1}}\right\},
$$

where $\epsilon\left(b_{t} / \bar{b}_{t}\right) \equiv \tilde{\epsilon}\left(b_{t} / \bar{b}_{t} ; b_{t} / \bar{b}_{t}\right)$. In the same way, the relationship between borrowing and saving rates can be written as

$$
\left(1+i_{t}^{b}\right)=\left(1+i_{t}\right) \cdot \phi\left(\frac{b_{t}}{\bar{b}_{t}}\right)
$$

where $\left(1+i_{t}^{j}\right)=\left(1+i_{t}^{b}\right)$ for each $j$ belonging to the mass of borrowers and where we have further defined $\phi\left(b_{t} / \bar{b}_{t}\right) \equiv \tilde{\phi}\left(b_{t} / \bar{b}_{t}, b_{t} / \bar{b}_{t}\right)$. 
The optimal supply of labor implies that the marginal rate of substitution between labor and consumption is equated to the real wage

$$
\frac{V_{l}\left(L_{t}^{j}\right)}{U_{c}\left(C_{t}^{j}\right)}=\frac{W_{t}^{j}}{P_{t}}
$$

for each agent $j$.

On the production side, we assume that there is a continuum of firms of measure one, each producing one of the goods in the economy. The production function is linear in labor, $Y(i)=L(i)$. Here we make another key simplifying assumption. ${ }^{10}$ We assume that production is a Cobb-Douglas indexes of the two types of labor as $L(i)=\left(L^{s}(i)\right)^{1-\chi}\left(L^{b}(i)\right)^{\chi}$. Given this technology, this implies that labor compensation for each type of worker is equal to total compensation $W_{j} L_{j}=W L$ where the aggregate wage index is appropriately defined by $W=\left(W^{s}\right)^{1-\chi}\left(W^{b}\right)^{\chi}$. This structure will greatly facilitate the aggregation of the model.

Given preferences, each firm faces a demand of the form $Y(i)=(P(i) / P)^{-\theta} Y$ where aggregate output is

$$
Y_{t}=(1-\chi) C_{t}^{s}+\chi C_{t}^{b}
$$

Firms are subject to price rigidities as in the Calvo model. A fraction of measure $(1-\alpha)$ of firms with $0<\alpha<1$ is allowed to change its price which is going to apply at a generic future period $T$ with a probability $\alpha^{T-t}$. Furthermore this price is going to be indexed to the inflation target over the period given by $\Pi^{T-t}$. Adjusting firms choose prices to maximize the presented discounted value of the profits under the circumstances that the prices chosen, appropriately indexed to the inflation target, will remain in place

$$
E_{t} \sum_{T=t}^{\infty}(\alpha \beta)^{T-t} \lambda_{T}\left[(1+\tau) \Pi^{T-t} \frac{P_{t}(i)}{P_{T}} Y_{T}(i)-\frac{W_{T}}{P_{T}} Y_{T}(i)\right]
$$

where $\lambda_{t}$ is a linear combination of the marginal utilities of real income of the two agents, $\lambda_{t}=\left[(1-\chi) U_{c}\left(C_{t}^{s}\right)+\chi U_{c}\left(C_{t}^{b}\right)\right]$, which is used to evaluate profits, since these are risk-shared across agents. Moreover $\tau$ is a constant

\footnotetext{
${ }^{10}$ This assumption makes our model a bit simpler than, for example, Curdia and Woodford (2011) and Eggertsson and Krugman (2012). In the latter work there is a labor supply effect of deleveraging which this assumption allows us to abstract from.
} 
subsidy on firms' revenues. The first-order condition of the optimal pricing problem implies

$$
\frac{P_{t}^{*}}{P_{t}}=\mu \frac{E_{t}\left\{\sum_{T=t}^{\infty}(\alpha \beta)^{T-t} \lambda_{T}\left(\frac{P_{T}}{P_{t}} \frac{1}{\Pi^{T-t}}\right)^{\theta} \frac{W_{T}}{P_{T}} Y_{T}\right\}}{E_{t}\left\{\sum_{T=t}^{\infty}(\alpha \beta)^{T-t} \lambda_{T}\left(\frac{P_{T}}{P_{t}} \frac{1}{\Pi^{T-t}}\right)^{\theta-1} Y_{T}\right\}}
$$

where $\mu \equiv \theta /[(\theta-1)(1+\tau)]$ and in equilibrium $P_{t}(i)=P_{t}^{*}$ since all firms adjusting their prices fix it at the same price. The remaining fraction $\alpha$ of firms, not chosen to adjust their prices, indexes their previously adjusted prices to the inflation target $\bar{\Pi}$. Calvo's model further implies the following law of motion for the general price index

$$
P_{t}^{1-\theta}=(1-\alpha) P_{t}^{* 1-\theta}+\alpha P_{t-1}^{1-\theta} \Pi^{1-\theta} .
$$

We assume that utility from consumption is exponential $u\left(C^{j}\right)=1-\exp \left(-z C^{j}\right)$ for some positive parameter $z$ while disutility of working is isoelastic $v\left(L^{j}\right)=$ $\left(L^{j}\right)^{1+\eta} /(1+\eta)$. These are convenient assumptions for aggregation and tractability purposes. We can see this by taking a weighted average of (14), for $j=s, b$, with weights $1-\chi$ and $\chi$, to obtain

$$
\frac{L_{t}^{\eta}}{z \exp \left(-z Y_{t}\right)}=\frac{W_{t}}{P_{t}}
$$

where aggregate output and labor are related through $Y_{t} \Delta_{t}=L_{t}$ and $\Delta_{t}$ is an index of price dispersion defined as

$$
\Delta_{t} \equiv \int_{0}^{1}\left(\frac{P_{t}(i)}{P_{t}}\right)^{-\theta} d i
$$

which follows the law of motion

$$
\Delta_{t}=\alpha\left(\frac{\Pi_{t}}{\Pi}\right)^{\theta} \Delta_{t-1}+(1-\alpha)\left(\frac{1-\alpha\left(\frac{\Pi_{t}}{\Pi}\right)^{\theta-1}}{1-\alpha}\right)^{\frac{\theta}{\theta-1}}
$$

To complete the characterization of the model we specify fiscal policy and assume that

$$
T_{t}^{j}=\tau P_{t} Y_{t}
$$

for each agent $j$ implying the government budget constraint

$$
(1-\chi) T_{t}^{s}+\chi T_{t}^{b}=\tau P_{t} Y_{t} .
$$

The model is closed with the specification of monetary policy. 


\subsection{Equilibrium conditions: A summary}

Here, we describe the equilibrium conditions of our model in a more synthetic way. On the demand side, Euler equations of savers and borrowers are

$$
\begin{gathered}
U_{c}\left(C_{t}^{s}\right)=\beta\left(1+i_{t}\right) E_{t}\left\{U_{c}\left(C_{t+1}^{s}\right) \frac{1}{\Pi_{t+1}}\right\}, \\
U_{c}\left(C_{t}^{b}\right)=\beta \frac{\left(1+i_{t}^{b}\right)}{1-\epsilon\left(\frac{b_{t}}{b_{t}}\right)} E_{t}\left\{U_{c}\left(C_{t+1}^{b}\right) \frac{1}{\Pi_{t+1}}\right\},
\end{gathered}
$$

where $\Pi_{t} \equiv P_{t} / P_{t-1}$.

Borrowing and saving rates are related through

$$
\left(1+i_{t}^{b}\right)=\left(1+i_{t}\right) \cdot \phi\left(\frac{b_{t}}{\bar{b}_{t}}\right)
$$

The dynamic of borrowing is described by the flow budget constraint of the borrowers

$$
\frac{b_{t}}{1+i_{t}^{b}}=\frac{b_{t-1}}{\Pi_{t}}+C_{t}^{b}-Y_{t}
$$

which follows from (9) where we have substituted in (20) and firms' profits, given by $\Psi_{t}^{j}=(1+\tau) P_{t} Y_{t}-W_{t} L_{t}$ noting that $W_{t} L_{t}=W_{t}^{j} L_{t}^{j}$. Moreover, we have set $\Gamma_{t}^{j}=0$ since intermediaries are held only by savers. ${ }^{11}$

Goods market equilibrium connects borrowers' and savers' consumption to real output

$$
Y_{t}=(1-\chi) C_{t}^{s}+\chi C_{t}^{b}
$$

The supply side of the model is characterized by the standard New-Keynesian aggregate-supply equation, written in a recursive form, obtained by combining equations $(16),(17),(18)$ together with $Y_{t}=\Delta_{t} L_{t}$

$$
\begin{gathered}
\left(\frac{1-\alpha\left(\frac{\Pi_{t}}{\Pi}\right)^{\theta-1}}{1-\alpha}\right)^{\frac{1}{\theta-1}}=\frac{F_{t}}{K_{t}}, \\
F_{t}=\lambda_{t} Y_{t}+\alpha \beta E_{t}\left\{F_{t+1}\left(\frac{\Pi_{t+1}}{\Pi}\right)^{\theta-1}\right\},
\end{gathered}
$$

\footnotetext{
${ }^{11}$ It should be noted that if profits of intermediation were also rebated to the borrowers, the relevant interest rate in (25) would be an appropriately weighted average of borrowing and saving rates.
} 


$$
K_{t}=\mu \frac{\lambda_{t} \Delta_{t}^{\eta} Y_{t}^{1+\eta}}{z \exp \left(-z Y_{t}\right)}+\alpha \beta E_{t}\left\{K_{t+1}\left(\frac{\Pi_{t+1}}{\Pi}\right)^{\theta}\right\}
$$

where

$$
\lambda_{t}=z\left[(1-\chi) \exp \left(-z C_{t}^{s}\right)+\chi \exp \left(-z C_{t}^{b}\right)\right]
$$

and

$$
\Delta_{t}=\alpha\left(\frac{\Pi_{t}}{\Pi}\right)^{\theta} \Delta_{t-1}+(1-\alpha)\left(\frac{1-\alpha\left(\frac{\Pi_{t}}{\Pi}\right)^{\theta-1}}{1-\alpha}\right)^{\frac{\theta}{\theta-1}}
$$

The above set of 10 equations (22) to (31) determines the equilibrium allocation for the following stochastic processes of 11 endogenous variables $\left\{C_{t}^{b}, C_{t}^{s}, i_{t}, i_{t}^{b}, b_{t}, Y_{t}, \Pi_{t}, F_{t}, K_{t}, \lambda_{t}, \Delta_{t}\right\}_{t=t_{0}}^{\infty}$ given initial condition on $b_{t_{0}-1}$ and $\Delta_{t_{0}-1}$ together with a policy rule and for given exogenous sequence $\left\{\bar{b}_{t}\right\}_{t=t_{0}}^{\infty}$ considering the zero lower bound on the nominal interest rate $i_{t} \geq 0$.

\subsection{Steady State}

Of particular importance is the steady state implied by the above equilibrium conditions, since we are approximating our model through log-linear

approximations. We consider an initial steady state in which $\bar{b}_{t}=\bar{b}^{\text {high }}$ and monetary policy sets inflation rate to the target $\Pi_{t}=\Pi$. It clearly follows from (31) that $\Delta_{t}=1$. In this steady state, the Euler equations of the savers, (22), and borrowers, (23), imply, respectively, that

$$
(1+i)=\beta^{-1} \Pi,
$$

and

$$
\left(1+i^{b}\right)=\beta^{-1} \Pi\left(1-\epsilon\left(\frac{b}{\bar{b}^{h i g h}}\right)\right)
$$

while the borrowing premium is given by

$$
\frac{\left(1+i^{b}\right)}{(1+i)}=\phi\left(\frac{b}{\bar{b}^{\text {high }}}\right)
$$

following equation (24).

Combining (32) to (34) we get

$$
\frac{\phi\left(\frac{b}{b^{h i g h}}\right)}{1-\epsilon\left(\frac{b}{b^{h i g h}}\right)}=1
$$


which implicitly defines the level of debt $b$, for each borrower, with respect to the risk-free threshold $\bar{b}^{\text {high }}$. In particular, under minor restrictions on the functions $\phi(\cdot)$ and $\epsilon(\cdot), b$ should be equal to $\bar{b}^{\text {high }}$ implying that $\phi(\cdot)=1$ so that borrowing and saving rates are equal in the steady state, $i^{b}=i$, while $\epsilon(\cdot)=0$. In terms of the original function describing the borrowing premium, as shown in (10), these results are consistent with the assumptions already made that $\tilde{\phi}(1,1)=1$ and $\tilde{\phi}_{b^{j}}(1,1)=0$, where the latter captures the fact that for each single borrower a change in their debt position with respect to the risk-free threshold has zero marginal effect on the premium.

Having determined the steady-state level of debt, we obtain the consumption of each borrower from (25)

$$
C^{b}=Y-\frac{(1-\beta)}{\Pi} \bar{b}^{h i g h},
$$

while from the aggregate resource constraint (26), we obtain consumption of savers

$$
C^{s}=Y+\frac{(1-\beta)}{\Pi} \frac{\chi}{1-\chi} \bar{b}^{h i g h} .
$$

Given the policy rule $\Pi_{t}=\Pi$, the aggregate-supply block of the model, characterized by equations (27)-(29), implies that steady-state output is determined by

$$
\frac{Y^{\eta}}{z \exp (-z Y)}=1
$$

where we have also assumed a subsidy on firms' revenues equal to $\tau=1 /(\theta-$ 1) such that $\mu=1$.

An important implication of our preference specification is that the steadystate level of output is independent of the distribution of wealth, and therefore of the debt deleveraging process. This is also the case for inflation and interest rates. In particular, we are interested in studying the effects of a permanent reduction in $\bar{b}$ from $\bar{b}^{\text {high }}$ to $\bar{b}^{\text {low }}$. Following this shock, output, inflation and interest rates will converge back to the initial steady state. Instead debt is going to reach the lower level $\bar{b}^{\text {low }}$, while accordingly consumption of savers and borrowers converge to new levels defined by

$$
\begin{gathered}
\bar{C}^{b}=Y-\frac{(1-\beta)}{\Pi} \bar{b}^{\text {low }}, \\
\bar{C}^{s}=Y+\frac{(1-\beta)}{\Pi} \frac{\chi}{1-\chi} \bar{b}^{\text {low }} .
\end{gathered}
$$




\section{A simple New-Keynesian model with het- erogenous agents}

Once we take a log-linear approximation of the equilibrium conditions around the above-defined steady state, our model takes a simple form and can represent a stylized version of New-Keynesian models with heterogenous agents and financial frictions. ${ }^{12}$

The Euler equations of savers (22) can be written as

$$
E_{t} \hat{C}_{t+1}^{s}-\hat{C}_{t}^{s}=\sigma\left[\hat{\imath}_{t}-E_{t}\left(\pi_{t+1}-\pi\right)\right]
$$

where we have defined $\hat{\imath}_{t} \equiv \ln \left(1+i_{t}\right) /(1+i), \pi_{t} \equiv \ln \Pi_{t}, \pi \equiv \ln \Pi$ and $\sigma \equiv 1 /(z Y)$. In particular, we are defining $\hat{C}_{t}^{j} \equiv\left(C_{t}^{j}-C^{j}\right) / Y$ for each $j=s, b$.

A first-order approximation of the Euler equation of the borrowers (23) implies

$$
E_{t} \hat{C}_{t+1}^{b}-\hat{C}_{t}^{b}=\sigma\left[\hat{\imath}_{t}^{b}+\lambda\left(\hat{b}_{t}-\hat{d}_{t}\right)-E_{t}\left(\pi_{t+1}-\pi\right)\right]
$$

where we have further defined $\hat{\imath}_{t}^{b} \equiv \ln \left(1+i_{t}^{b}\right) /(1+i), \hat{b}_{t} \equiv\left(b_{t}-\bar{b}^{h i g h}\right) / \bar{b}^{h i g h}$, $\hat{d}_{t} \equiv\left(\bar{b}_{t}-\bar{b}^{h i g h}\right) / \bar{b}^{h i g h}$ while $\lambda \equiv \varepsilon_{b}(1)>0 .{ }^{13}$

The spread (24) between borrowing and saving rates can be approximated as

$$
\hat{\imath}_{t}^{b}=\hat{\imath}_{t}+\varphi\left(\hat{b}_{t}-\hat{d}_{t}\right)
$$

where $\varphi \equiv \phi_{b}(1)>0$ is the steady-state elasticity of the premium $\phi$ with respect to real debt. ${ }^{14}$

A first-order approximation of the budget constraint of the borrowers (25) delivers

$$
\hat{C}_{t}^{b}=\frac{\tilde{b}}{(1+i)}\left(\hat{b}_{t}-\hat{\imath}_{t}^{b}\right)-\frac{\tilde{b}}{\beta(1+i)}\left(\hat{b}_{t-1}-\left(\pi_{t}-\pi\right)\right)+\hat{Y}_{t}
$$

where $\hat{Y}_{t} \equiv\left(Y_{t}-Y\right) / Y$ and $\tilde{b} \equiv \bar{b}^{h i g h} / Y$.

\footnotetext{
${ }^{12}$ Curdia and Woodford $(2010,2011)$ are examples of similar models through alternative modelling assumptions.

${ }^{13}$ Note that the assumption already made that $\tilde{\phi}_{b^{i}, b}(1,1)+\tilde{\phi}_{b^{i}, b^{i}}(1,1)>0$ implies that $\lambda>0$.

${ }^{14}$ Note that $\phi_{b}(1)=\tilde{\phi}_{b^{j}}(1,1)+\tilde{\phi}_{b}(1,1)$. Since $\tilde{\phi}_{b^{j}}(1,1)=0$, the assumption already made that $\tilde{\phi}_{b}(1,1)>0$ is needed to obtain $\varphi>0$.
} 
Goods market equilibrium (26) implies

$$
\hat{Y}_{t}=\chi \hat{C}_{t}^{b}+(1-\chi) \hat{C}_{t}^{s}
$$

Equations (35), (36) together with (37), (38) and (39) constitute the aggregate demand block of the model.

In a log-linear approximation, the supply block can be derived by approximating (27)-(29), noting that $\Delta_{t}$ is a second-order term, to obtain the standard New-Keynesian Phillips curve

$$
\pi_{t}-\pi=\kappa \hat{Y}_{t}+\beta E_{t}\left(\pi_{t+1}-\pi\right)
$$

where we have defined $\kappa \equiv(1-\alpha)(1-\alpha \beta)\left(\eta+\sigma^{-1}\right) / \alpha .^{15}$

Equations (35), (36) together with (37), (38), (39) and (40) determine the equilibrium allocation for $\left\{\pi_{t}, \hat{C}_{t}^{b}, \hat{C}_{t}^{s}, \hat{Y}_{t}, \hat{\imath}_{t}^{b}, \hat{\imath}_{t}, \hat{b}_{t}\right\}_{t=t_{0}}^{\infty}$ given the specification of monetary policy and given exogenous process $\hat{d}_{t}$ and initial condition $\hat{b}_{t_{0}-1}$.

\subsection{A parallel with the textbook New-Keynesian model}

Before going further it is useful to now explore the interpretation of the results we have already obtained in the linearized model. In particular we can now show that the model we have just sketched out generalizes the standard New Keynesian model common in economic textbooks. To see this, let us combine equations (35), (36), (37) and (39) to yield

$$
\hat{Y}_{t}=E_{t} \hat{Y}_{t+1}-\sigma\left(\hat{\imath}_{t}-E_{t}\left(\pi_{t+1}-\pi\right)-r_{t}^{n}\right)
$$

where $r_{t}^{n}$ is now given by

$$
r_{t}^{n} \equiv-\chi(\lambda+\varphi)\left(\hat{b}_{t}-\hat{d}_{t}\right)
$$

Meanwhile the AS equation is exactly the same as in the standard model, as we see in (40). In the standard model then $r_{t}^{n}$ is exogenous so that given a policy rule for the nominal interest rate one can characterize an equilibrium in the model. Here we see, however, that $r_{t}^{n}$ is endogenously determined. Hence,

\footnotetext{
${ }^{15}$ Given the preferences' specification assumed, the way wealth is distributed across the two types of agents does not enter directly into the log-linear version of the AS equation, as instead in Curdia and Woodford (2010).
} 
even if demand is still determined by the real interest rate and expected future income, the level of private indebtedness will now shift this standard demand relationship. In particular if the real value of private debt, $\hat{b}_{t}$, is above the "target" value $\hat{d}_{t}$ then private debt is too high, triggering a negative shock to the natural rate of interest, i.e., a negative shock to demand. Equivalently if $\hat{b}_{t}$ is below $\hat{d}_{t}$ then there is extra room for the indebted agents to spend, which acts as a positive demand shock.

Observe, however, that although $\hat{d}_{t}$ is exogenous in the model, $\hat{b}_{t}$ is endogenously determined. To solve for this variable, however, we need to solve the entire model using the set of equations summarized in the last section.

\section{Dynamic deleveraging when there are no other frictions}

We now consider the effect of a deleveraging shock in the model. Before moving onto analyzing the full model that incorporates the zero bound it is worth considering how the model behaves in its absence when the central bank can successfully target inflation. Here we assume that the central bank will set its interest rate at all time so as to achieve a 2 percent inflation target $\pi$ around which our model was linearized (and the firms index their prices according to).

We parameterize the model as shown in Table 1

Table 1: Calibration

\begin{tabular}{ccccc}
\hline \hline$\beta=0.9938$ & $\sigma=0.5$ & $\varphi=0.144$ & $\lambda=0.1728$ & $\chi=0.4$ \\
$\eta=1$ & $\kappa=0.02$ & $\bar{b}^{\text {high }}=6.2431$ & $\bar{b}^{\text {low }}=5.0985$ & $\tilde{b}=12$
\end{tabular}

In particular, we set initial aggregate debt over GDP (at annual rates), defined as $b^{g d p}$, to $120 \%$, i.e. $b^{g d p}=\left(\chi \bar{b}^{h i g h}\right) /(4 y)=1.2$ which implies setting $\tilde{b}=\bar{b}^{h i g h} / y=(4 \times 1.2) / \chi=12$.

The following process for $\hat{d}_{t}$ is assumed:

$$
\hat{d}_{t+1}=\hat{d}_{t}+\epsilon_{t+1}
$$


We are analyzing the transition between two steady states where at time $1 \bar{b}$ moves from $\bar{b}^{\text {high }}$ to $\bar{b}^{\text {low }}$ permanently in an unexpected way. The idea is that this shock corresponds to a deleveraging cycle, in the sense that borrowing at the level $\bar{b}^{\text {high }}$ turns out (ex post and unanticipatedly) not to be supported by fundamentals. Thus there is a Minsky moment in which $\bar{b}^{\text {high }} \rightarrow \bar{b}^{\text {low }}$ triggering the dynamics we will now see. In the context of the process above, this simply corresponds to one time shock $\epsilon_{1}<0 .{ }^{16}$ In particular, given the above parametrization, private debt to output moves from $120 \%$ to $98 \%$ after deleveraging in line with what has been experienced by the private sector of the U.S. economy in the aftermath of the recent financial crisis.

Figure 3 shows the dynamics in the case the central bank successfully targets two percent inflation, and the zero bound is not imposed. Equivalently we can interpret this as the equilibrium allocation if all prices were flexible. This experiment is helpful to clarify the main forces in the model in response to a deleveraging shocks if other frictions play no role.

In response to a deleveraging shock we see that first there is an increase in the spread between the borrowing and the saving rate, $i_{t}^{b}$ and $i_{t}$ respectively, that is triggered by the exogenous shock $\bar{b}_{t}$. In response to this the borrowers find it optimal to start paying down their debt - deleverage - so we see a decline in their outstanding debt $b_{t}$ in Figure 4. How do the borrowers deleverage? In equilibrium they do so by doing two things: By cutting down their consumption, $C_{t}^{b}$, and by increasing their hours worked, $L_{t}^{b}$. Note, however, that this is perfectly offset by a drop in hours by the savers and an increase in their consumption. It is clear why the borrowers decide to deleverage - they are facing higher borrowing costs. But why do the savers increase their consumption and cut back their hours? The reason is that the risk-free interest rate, $i_{t}^{s}$, declines, which means that consumption today is now relatively less expensive than it was before. This price change is a key to understand the problem we shall see once we add more frictions to the model, because if there is a bound on how much this interest rate can decline (due to the zero bound) that can create serious problems for macroeconomic management. We can also see that the saver finds it in his interest to cut back hours. The reason is that the higher consumption of the saver reduces his marginal utility of consumption, in turn reducing his incentive to supply work. ${ }^{17}$

\footnotetext{
${ }^{16}$ Recall the definition $\hat{d}_{t} \equiv\left(\bar{b}_{t}-\bar{b}^{h i g h}\right) / \bar{b}^{\text {high }}$.

${ }^{17}$ Real wages of savers increase following the shock, and offset in part the wealth effect
} 

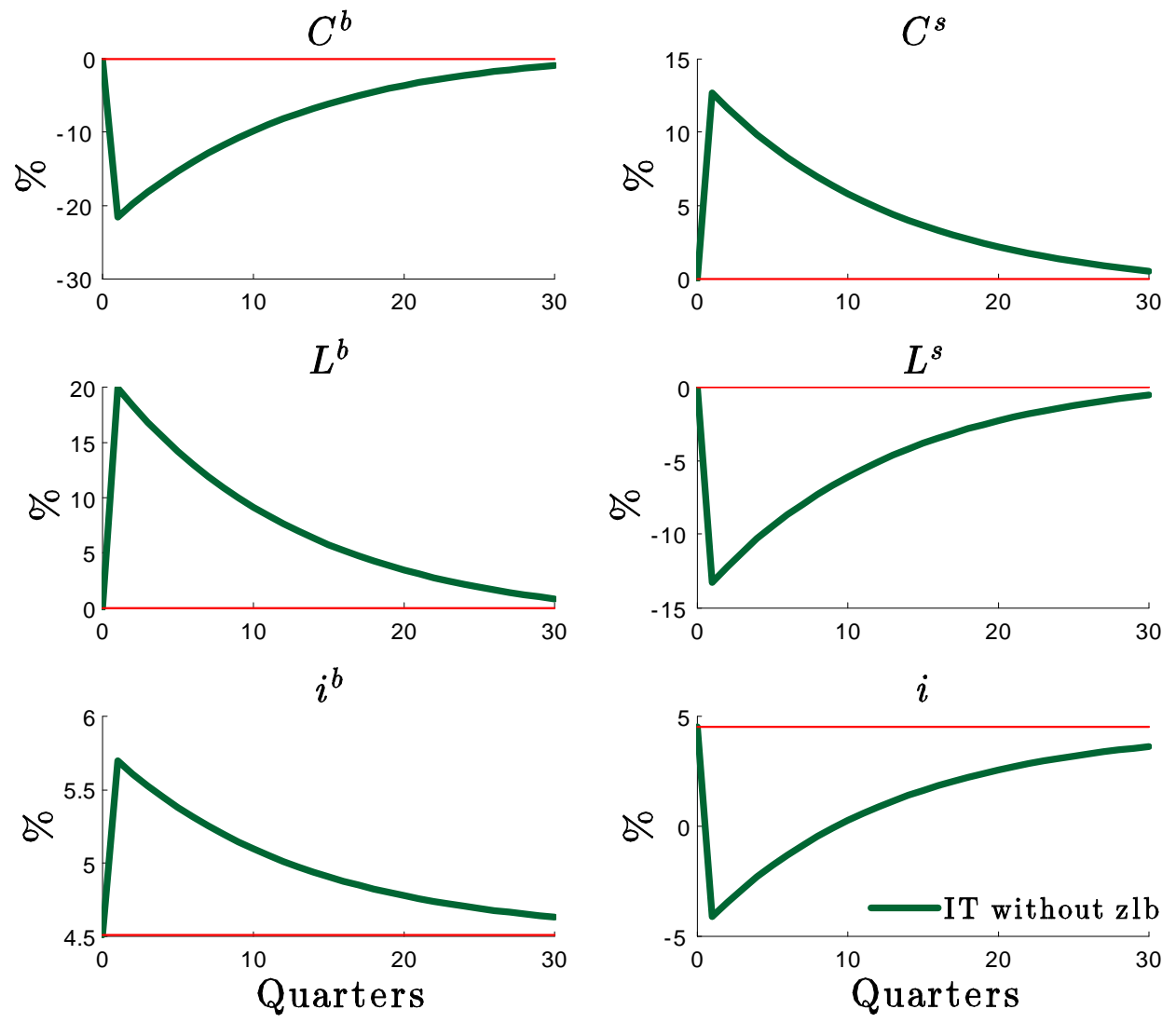

Figure 3: Responses following a deleveraging shock when the central bank can target constant inflation (or prices are flexible) without taking in consideration the zero-lower bound (line "IT without zlb"). Variables are: consumption of borrowers $\left(C^{b}\right)$, consumption of savers $\left(C^{s}\right)$, hours worked of borrowers $\left(L^{b}\right)$, hours worked of savers $\left(L^{s}\right)$, nominal interest rate on borrowing $\left(i^{b}\right)$, nominal interest rate on saving $(i) . C^{b}, C^{s}, L^{b}, L^{s}$ are in percentage deviation with respect to the steady state; $i^{b}$ and $i$ are in percent and at annual rates. 

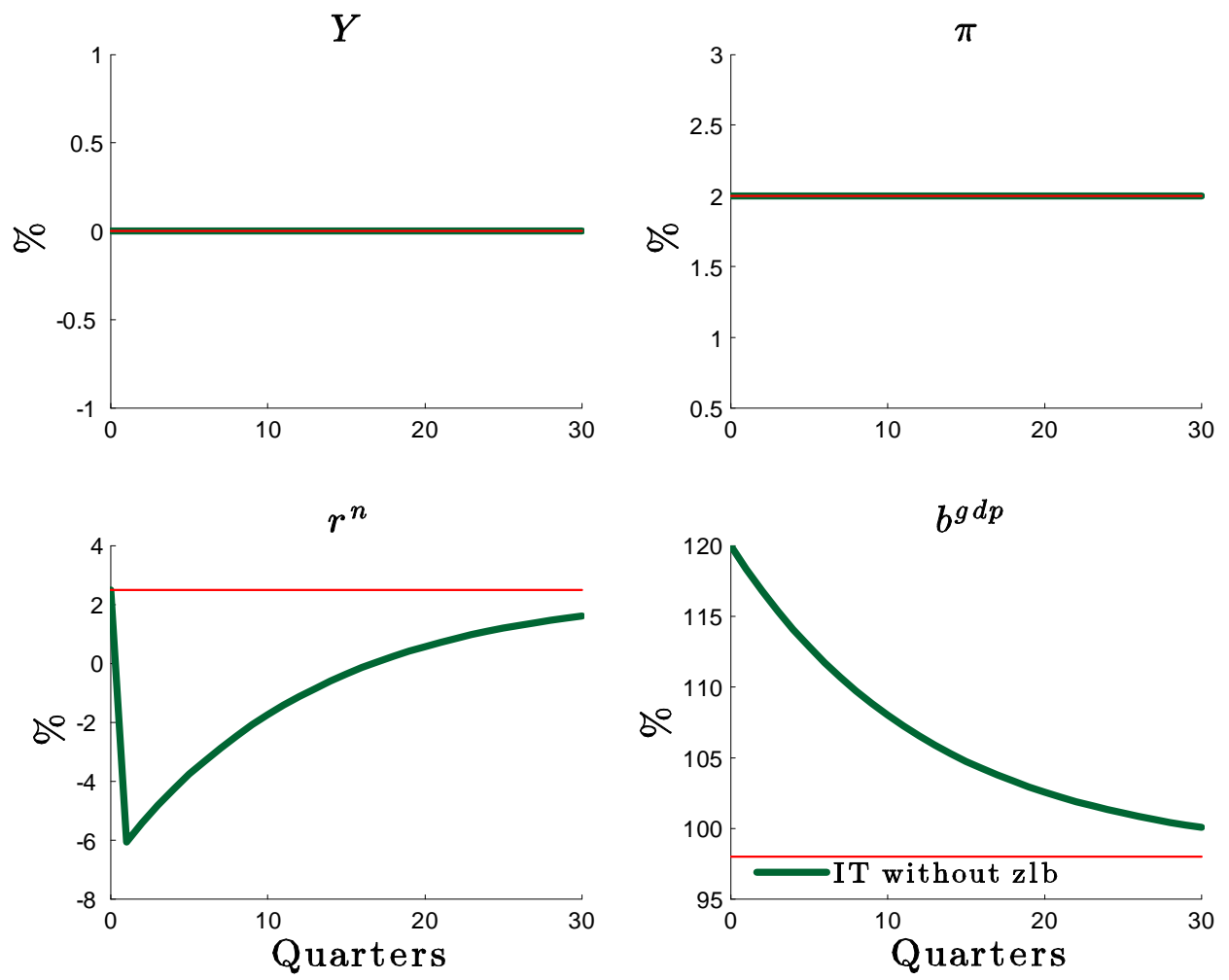

Figure 4: Responses following a deleveraging shock when the central bank can target constant inflation (or prices are flexible) without taking in consideration the zero-lower bound (line "IT without zlb"). Variables are: output $(Y)$, inflation rate $(\pi)$, natural rate of interest defined as in (42) $\left(r^{n}\right)$, aggregate debt to GDP $\left(b^{g d p}\right) . Y$ is in percentage deviation with respect to the steady state; $\pi, r^{n}$ and $b^{g d p}$ are in percent and at annual rates. 
Under perfectly flexible prices (or a central bank that can target a constant inflation target regardless of the zero bound) the deleveraging shock has no effect on either output or inflation as we see in Figure 4. As we already noted, this is because the real rate adjusts so as to make the savers increase their spending to make up for the drop in spending by the borrowers, while marginal utility of consumption adjusts to make the savers cut back on their labor hours to offset the increase in labor hours by the borrowers. In equilibrium, output is unchanged. Figure 4 shows by how much the real interest rate needs to drop for this to happen, we see that it drops by about 6 percentage points.

The real interest rates that are consistent with this equilibrium, however, are negative. For a central bank that targets inflation at 2 percent (as we assume here) this means that if the natural rate of interest is below $-2 \%$ then the zero bound becomes binding and the equilibrium adjustment we have just explored is not feasible. This is the case we now turn to analyze.

\section{Dynamic deleveraging at the zero bound}

The key to the adjustment mechanism in response to a deleveraging shock, outlined in the last section, was that, in response to cutbacks in spending by the borrower, the risk-free interest rate declines, which induced the savers to make up for this drop in spending. As revealed in Figure 4, however, this adjustment implies a negative interest rate faced by the saver, which we assume is the rate controlled by the central bank. At two percent inflation target, the real saving rate can be at -2 percent, even if the nominal rate is zero. It can't go any further than that, however, which is needed in our example, as shown in Figure 4. Hence the zero bound is violated.

Figure 5 shows the corresponding output drop and deflation that is triggered by the fact that the central bank cannot accommodate the shock. As we can see the dynamic deleveraging story gives a relatively natural way to thinking about this scenario, although the green line is quite similar to what has been observed in comparative examples in the New Keynesian model with exogenous preference shock.

There is a new element of dynamic deleveraging, however, which is most clear in Figure 5. Because the zero bound is now binding, this reduces output

on their labor supply. Without the increase in real wages, labor supply would fall twice as low. 

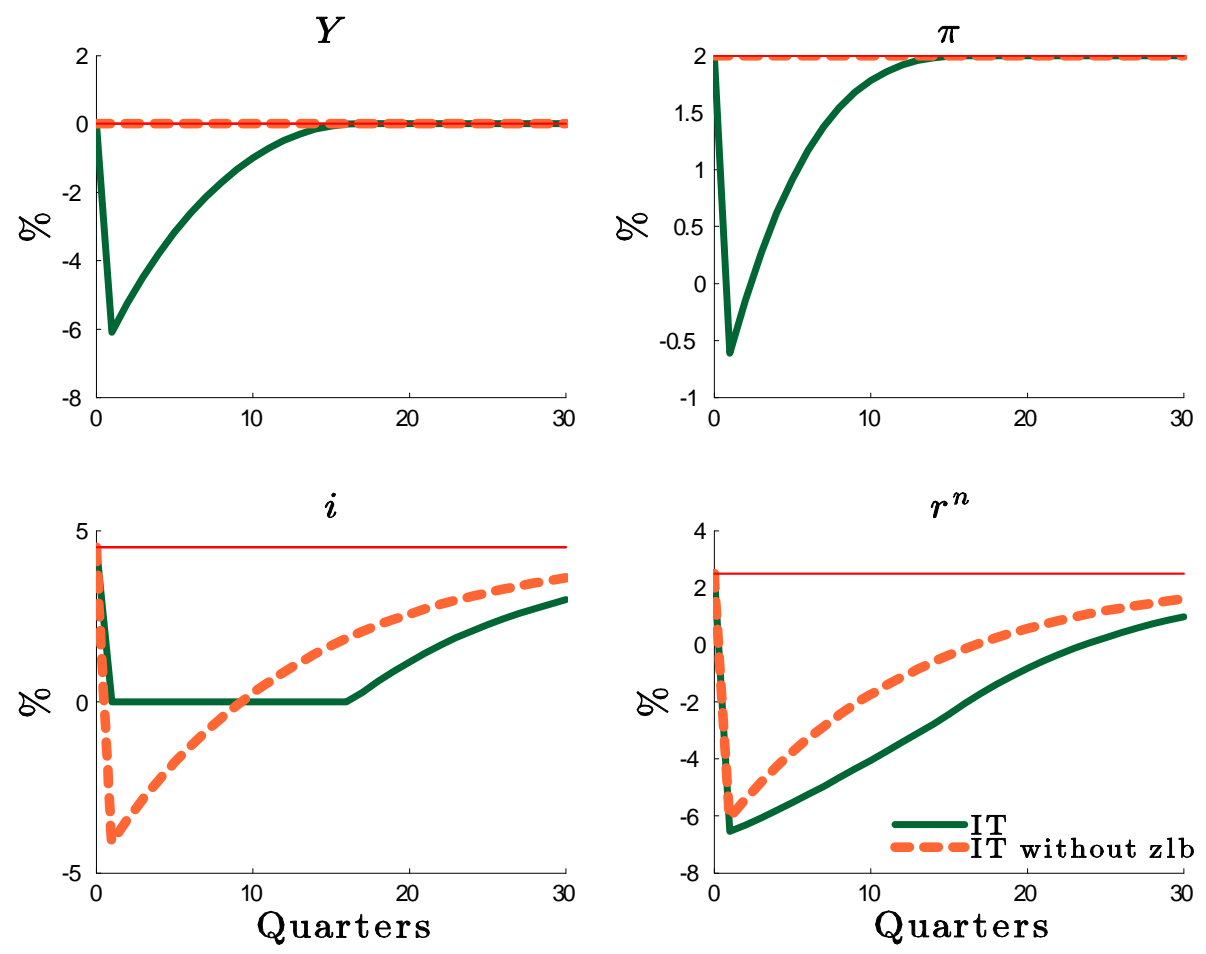

Figure 5: Responses following a deleveraging shock if the central bank can target constant inflation by taking in consideration (line "IT") and without taking in consideration (line "IT without zlb") the zero-lower bound. Variables are: output $(Y)$, inflation rate $(\pi)$, nominal interest rate on savings $(i)$, natural rate of interest defined as in $(42)\left(r^{n}\right) . Y$ is in percentage deviation with respect to the steady state; $\pi, r^{n}, i$ and are in percent and at annual rates. 
and thus the income of the borrowers. This, in turn, implies a slowdown in the pace of deleveraging. A simple way of seeing this is to compute the statistic (42) that maps into the natural rate of interest of the standard New Keynesian model. The key point is that this process is now endogenous and, as we can see in Figure 5, the crisis means that it recovers more slowly (green line) than if policy had been able to accommodate it fully. What this means is that endogenous deleveraging increases the persistence of the crisis by creating a feedback between falling in income with a slowdown in deleveraging.

Another way to see this is to conduce a slightly different thought experiment in comparing the standard New-Keynesian model to the current model, an experiment we now turn to.

\section{Zero inflation target with and without en- dogenous deleveraging}

Consider the following thought experiment: Let us extract the real interest rate - or the natural rate of interest - from the model of Section 4. This is the natural rate of interest in our model in the case that monetary policy is able to target inflation at 2 percent when we ignore the zero bound. Putting it differently, we can directly back this variable out of equation (42) and this variable is what is shown in Figure 4.

If we treat this sequence of numbers as an exogenous variable into the standard NK model described in Section 3.1 and ignore the zero bound we obtain exactly the same solution as before, namely no output gap and inflation at target. But we can now also impose the zero bound in that model too, and compare with our previous solution of Section 5, and ask what happens. In the standard NK model, we are keeping the natural rate of interest as purely exogenous and it follows the path shown in Figure 4. By comparing the two outcomes we are then seeing what making the natural rate of interest endogenous does to our solution. That is, we can infer to what extent it matters that in our new model the drop in output leads to an endogenous propagation by making it harder for the borrowers to deleverage, thus delaying the recovery of the natural rate of interest to its steady state and prolonging the crisis.

Figure 6 shows the evolution of output, inflation, the natural interest rate 

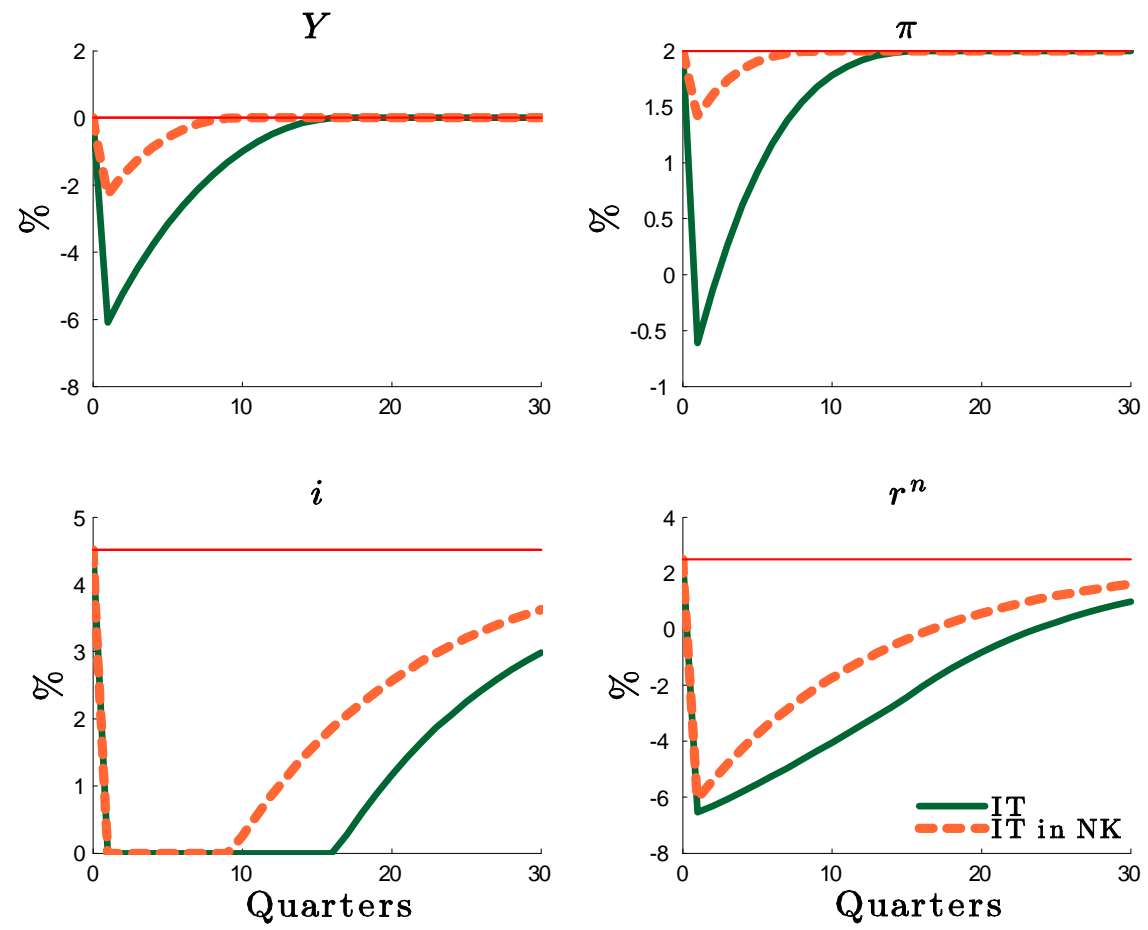

Figure 6: Comparison between the responses to a deleveraging shock in the deleveraging model, under inflation targeting and considering the zero-lower bound (line "IT"), with those of the benchmark New-Keynesian model of Section 3.1, under inflation targeting and considering the zero-lower bound (line "IT in NK"). (The responses of the two models coincide under inflation targeting without considering the zero-lower bound). Variables are: output $(Y)$, inflation rate $(\pi)$, nominal interest rate on savings $(i)$, natural rate of interest defined as in (42) $\left(r^{n}\right) . Y$ is in percentage deviation with respect to the steady state; $\pi, i$ and $r^{n}$ are in percent and at annual rates. 
and the nominal interest rate in the standard NK model (orange dashed line) and compares it to the dynamic deleveraging model (green line) where we have constructed the shocks as described above. We parameterize the NK model exactly like our current one, using the mapping shown in Section 3.1. We see that with endogenous deleveraging both the effects on output and inflation are bigger than in the standard case (and note that in the absence of the zero bound each of the variables would have behaved exactly the same). The reason is that under dynamic deleveraging then the output slacks lower the natural rate of interest further, and makes it more persistent, leading to the zero bound being even more binding. Since aggregate demand depends on the current and expected future nominal interest rate, expected inflation and expected output, this feeds into lower demand today, thus lower output and inflation and so on. We see that quantitatively this effect is quite large.

Hence we conclude that adding dynamic deleveraging can have large impacts on the actual dynamics at the zero bound, both in terms of the persistence of the crisis (for a given shock as measured by the natural rate of interest) and its impact. But what is the implication of this for optimal monetary policy? That is the issue we now analyze.

\section{Optimal policy under dynamic deleverag- ing}

To consider optimal monetary policy, we first need to study how social welfare looks in our model. We consider a benevolent policymaker maximizing the utility of the households in the economy

$$
W_{t}=E_{t}\left\{\sum_{t=t_{0}}^{\infty} \beta^{T-t}\left[\tilde{\chi}\left(U\left(C_{t}^{s}\right)-V\left(L_{t}^{s}\right)\right)+(1-\tilde{\chi})\left(U\left(C_{t}^{b}\right)-V\left(L_{t}^{b}\right)\right)\right]\right\}
$$

for a generic weight $\tilde{\chi} \in(0,1)$. In particular, we choose this weight in a way that the final steady state is efficient. This means that our deleveraging experiment brings the economy from an inefficient distribution of wealth to an efficient one. We consider a second-order approximation of the above welfare function around this efficient steady state. Recall that the efficient steady-state level of output does not depend on the weight $\tilde{\chi}$, while the steady-state levels of consumption for each agent are instead a function of the distribution of wealth and therefore depend on $\tilde{\chi}$. The efficient steady 
state is implicitly defined by the first-order conditions of the optimization problem implied by the maximization of (43) under the resource constraint

$$
Y_{t}=\left(L_{t}^{s}\right)^{\chi}\left(L_{t}^{b}\right)^{1-\chi}=\chi C_{t}^{s}+(1-\chi) C_{t}^{b} .
$$

In the Appendix, we show that the second-order approximation of (43) is equivalent to the following quadratic loss function

$$
L_{t_{0}}=\frac{1}{2} E_{t}\left\{\sum_{t=t_{0}}^{\infty} \beta^{t-t_{0}}\left[\hat{Y}_{t}^{2}+\chi(1-\chi) \lambda_{c}\left(\tilde{C}_{t}^{b}-\tilde{C}_{t}^{s}\right)^{2}+\lambda_{\pi}\left(\pi_{t}-\pi\right)^{2}\right]\right\} .
$$

The benevolent policymaker is concerned about the deviations of output and inflation from their respective steady states as it is standard in the literature. However, there is an additional and new term in the loss function capturing the deviations of consumption of the borrowers and savers from their respective efficient steady state. We have defined $\tilde{C}_{t}^{j} \equiv\left(C_{t}^{j}-\bar{C}^{j}\right) / Y$ for each $j$ where $\bar{C}^{j}$ is indeed the efficient steady-state level.

We can also write these latter terms with respect to the initial steady state obtaining equivalently

$$
L_{t_{0}}=\frac{1}{2} E_{t}\left\{\sum_{t=t_{0}}^{\infty} \beta^{t-t_{0}}\left[\hat{Y}_{t}^{2}+\chi(1-\chi) \lambda_{c}\left(\hat{C}_{t}^{b}-\hat{C}_{t}^{s}-c^{R}\right)^{2}+\lambda_{\pi}\left(\pi_{t}-\pi\right)^{2}\right]\right\}
$$

where $c^{R}$ captures the relative difference between the initial and final steadystate consumption of borrowers and savers defined as $c^{R} \equiv\left[\left(C^{b}-\bar{C}^{b}\right)-\left(C^{s}-\right.\right.$ $\left.\left.\bar{C}^{s}\right)\right] / Y$.

In our model, the AS equation (40) shows that there is no trade-off between stabilizing output and inflation since there are no cost-push shocks or other features which would otherwise create this trade-off. However, the above loss function presents an additional term which captures the costs of imperfect risk-sharing. These costs are zero when the consumption of each agent is at its efficient steady state. However, the initial debt distribution is not efficient and therefore risk-sharing is imperfect in the initial steady state. The deleveraging shock, which we are considering, brings the economy from an inefficient debt distribution to an efficient one.

In what follows, we are going to analyze which monetary policy allows to achieve a better adjustment according to the loss function (45). Clearly, the policymaker would like to keep inflation and output on target and at 

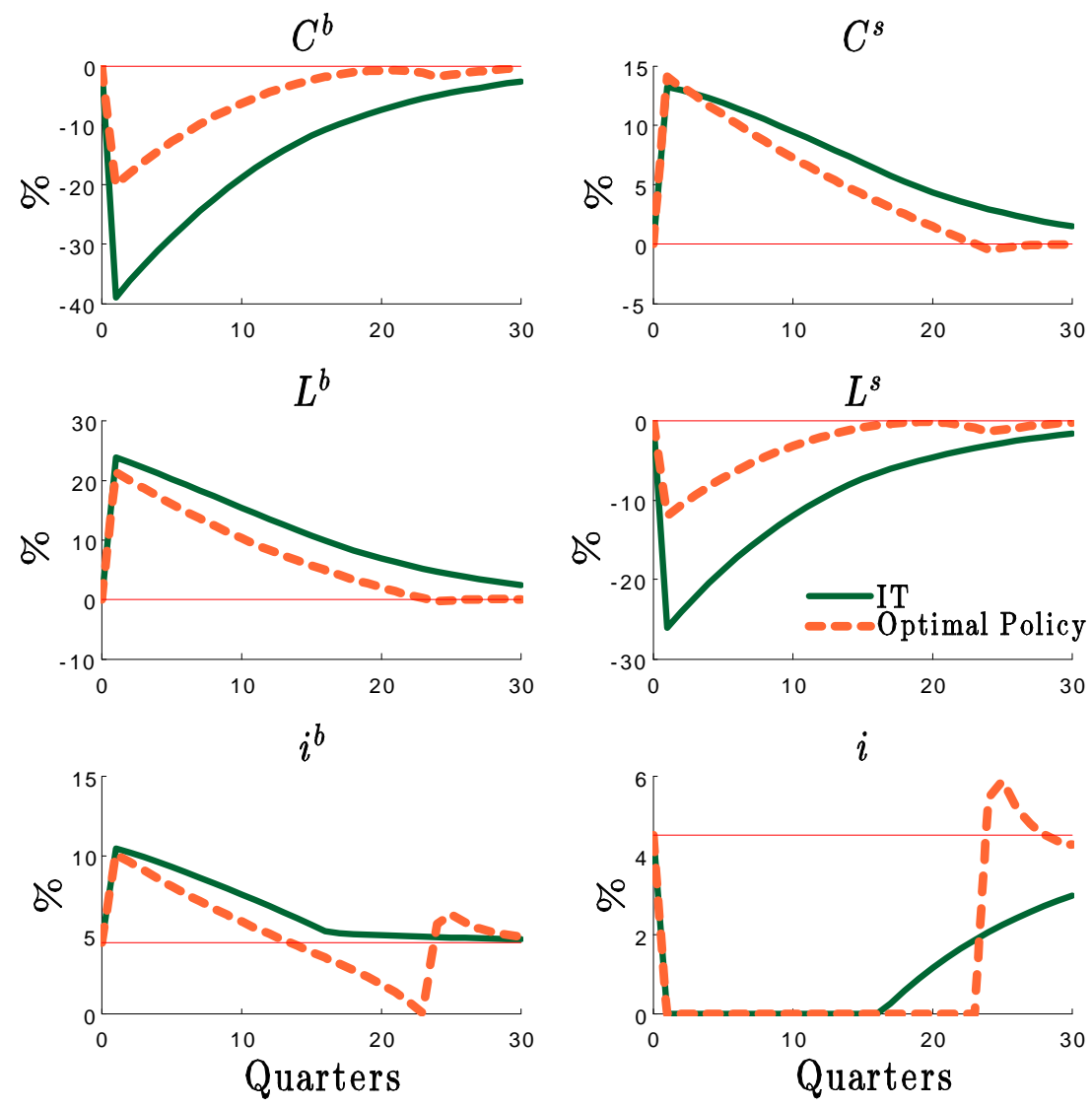

Figure 7: Responses following a deleveraging shock under optimal monetary policy with commitment (line "Optimal Policy") in comparison to inflationtargeting policy (line "IT") taking in consideration the zero-lower bound. Variables are: consumption of borrowers $\left(C^{b}\right)$, consumption of savers $\left(C^{s}\right)$, hours worked of borrowers $\left(L^{b}\right)$, hours worked of savers $\left(L^{s}\right)$, nominal interest rate on borrowing $\left(i^{b}\right)$, nominal interest rate on saving $(i) . C^{b}, C^{s}, L^{b}, L^{s}$ are in percentage deviation with respect to the steady state; $i^{b}$ and $i$ are in percent and at annual rates. 

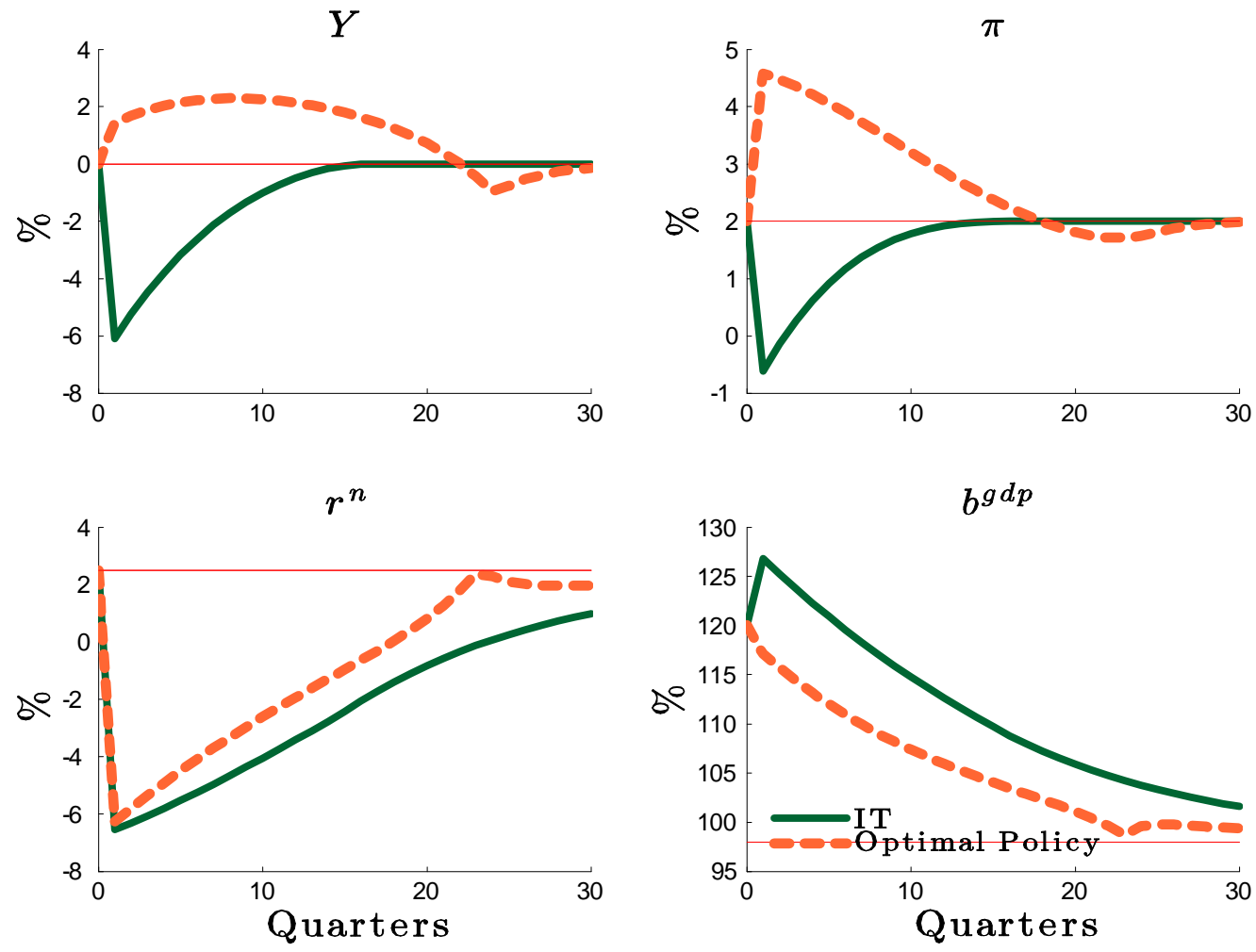

Figure 8: Responses following a deleveraging shock under optimal monetary policy with commitment (line "Optimal Policy") in comparison to inflationtargeting policy (line "IT") taking in consideration the zero-lower bound. Variables are: output $(Y)$, inflation rate $(\pi)$, natural rate of interest defined as in $(42)\left(r^{n}\right)$, aggregate debt to GDP $\left(b^{g d p}\right) . Y$ is in percentage deviation with respect to the steady state; $\pi, r^{n}$ and $b^{g d p}$ are in percent and at annual rates. 
the same time achieve immediately the efficient levels of consumption for the two agents. However, the three objectives can only be simultaneously reached in the long run. As shown in Section 4 and in particular in Figure 3, a deleveraging shock under an inflation-targeting policy produces short-run divergences between the consumption of borrowers and savers which are in contrast with the objective in (45), even without taking into account the zero-lower bound. And adding the zero-lower bound makes things worse since output also drops as shown in Section 5 and Figure 5.

Optimal policy under commitment minimizes the loss function (45) by choosing the sequences $\left\{\pi_{t}, \hat{C}_{t}^{b}, \hat{C}_{t}^{s}, \hat{Y}_{t}, \hat{\imath}_{t}^{b}, \hat{\imath}_{t}, \hat{b}_{t}\right\}_{t=t_{0}}^{\infty}$ under the constraints (35), $(36),(37),(38),(39)$ and (40) given exogenous process $\hat{d}_{t}$ and initial condition $\hat{b}_{t_{0}-1}$, taking into account the zero-lower bound constraint on the nominal interest rate. Details on the first-order conditions of the optimal policy problem are left to the Appendix.

Figures 7 and 8 show the responses of some variables of interest to a permanent shock on $\bar{b}_{t}$, and therefore on $\hat{d}_{t}$, under optimal policy and inflation targeting considering the zero bound on nominal interest rates. We can see that optimal policy can have a larger effect in the model than the case in which it targets constant inflation. The way optimal policy works is to a large extent similar to that in the standard NK model (see e.g. Eggertsson and Woodford (2003)). In particular, as shown in Figure 8, optimal policy involves committing to keep the nominal interest rate low for a substantial period of time longer than if the central bank is an inflation targeter. The result of this commitment is a modest output boom and inflation during and after the trap. A key difference, however, is that this commitment is to some extent even stronger than in the standard model, as it implies an accommodation that is forceful enough that inflation overshoots the 2 percent target throughout the duration of the zero bound, and slightly undershoots it after. This feature of optimal policy is new and different relatively to the standard model, which we will now elaborate on, and is mostly because of the new terms in the social welfare function brought about by dynamic deleveraging. 

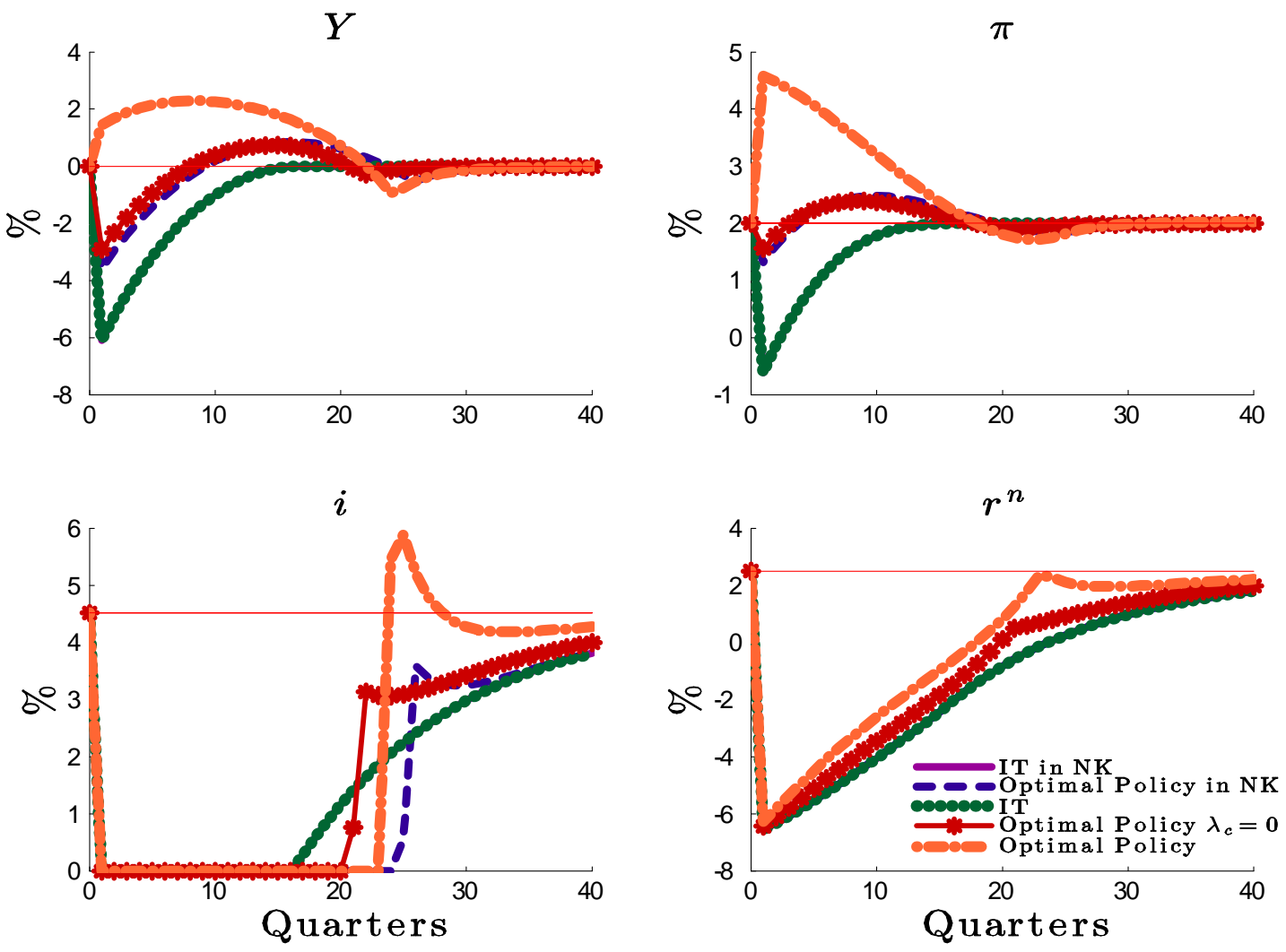

Figure 9: Comparison between the responses to a deleveraging shock. "Optimal Policy": optimal policy under commitment in the deleveraging model. "Optimal Policy $\lambda_{c}=0$ ": optimal policy under commitment in the deleveraging model when $\lambda_{c}=0$ in (46). "IT": inflation-targeting policy considering the zero-lower bound in the deleveraging model. "Optimal Policy in NK": optimal policy in the standard NK model. "IT in NK": inflation-targeting policy in the standard NK model. (The responses of "IT" and "IT in NK" coincide by construction). Variables are: output $(Y)$, inflation rate $(\pi)$, nominal interest rate on savings $(i)$, natural rate of interest defined as in (42) $\left(r^{n}\right) . Y$ is in percentage deviation with respect to the steady state; $\pi,, i$ and $\mathrm{r}^{n}$ are in percent and at annual rates. 


\subsection{Comparison to optimal policy in the standard NK model}

We compare the basic NK model to our baseline model. To do this we compute the natural rate of interest from equation (42) assuming that the central bank follows a strict inflation target and hits the zero bound. This is the basic exercise we carried out in Figure 5. If we feed this process into the standard NK model and assume that there it is exogenous, it is easy to see that the solution of the NK model, under inflation targeting and considering the zero-lower bound, is exactly the same as we already have in our model as shown in Figure 5. To see this, notice that both models satisfy exactly the same equations (40) and (41) and that the process $r_{t}^{n}$ across the two simulations is by construction exactly the same. This baseline case - which is the same across the two models - is reported in Figure 9 via a green line (the purple line denoted "IT in NK" is not visible because it is exactly the same as the green line). It is interesting now to ask: How does the optimal monetary policy look across the two models? And should we expect it to be different? To make the comparison more clean we first assume that policy is set using the same objective: our more general model has an objective that coincides with the standard one when $\lambda_{c}=0$ in (46) (in which case the government does not care about redistribution across the two agents). The answer is shown in Figure 9. As we can see, optimal policy under dynamic deleveraging (but with the same objective as the standard NK model, the line "Optimal Policy $\lambda_{c}=0$ ") yields very similar dynamics to the standard NK model (the line "Optimal Policy NK") with three important wrinkles. First, both inflation and output overshoot their long term value a little bit earlier than in the standard case (and before the zero bound stops being binding). Second, we see that the optimal policy has the effect of increasing the natural rate of interest above the level we feed exogenously into the NK model (in the latter it corresponds to the green-dotted line in the panel on the natural rate). Third, and this is related to the second point, we see that the optimal policy now prescribes a shorter duration of the zero interest rate than in the NK model. The reason for this last point is not that the policy is

less aggressive. Instead - it is because it is successful in endogenously raising the natural rate of interest and generating an output boom and inflation that the liftoff of rates is now earlier than it was in the absence of the policy easing.

This particular feature of optimal policy under dynamic deleveraging is 
amplified even further using the true social objective that also puts value on consumption insurance across the different types of agents in the model. We also see this in the figure (line "Optimal Policy"), which suggests that the fully optimal policy is aggressive enough to bring about immediate increase of output and inflation in the liquidity trap to an extent that it is about 4.5 percent on impact, thus overshooting the implicit inflation target of the central bank by a substantial amount.

\section{Government Spending}

Monetary policy works through a commitment to actions in the future that may be dynamically inconsistent. Accordingly, many are skeptical about the extent to which it has an impact which, in any event, is highly dependent on the credibility of the central bank. A policy that is not subject to this problem to the same extent is fiscal policy, because it involves taking direct actions today. For this reason we here consider a simple experiment in which monetary policy is constrained by targeting the inflation target of 2 percent, while we model fiscal policy as being able to react directly to the shock. We define $G$ the public expenditure which now enters aggregate demand

$$
Y_{t}=(1-\chi) C_{t}^{s}+\chi C_{t}^{b}+G_{t} .
$$

We assume that public expenditure is financed with lump-sum taxes. In particular we set the following distribution of taxes between borrowers and savers

$$
\begin{gathered}
T_{t}^{b}=\frac{\omega}{\chi} G_{t}+\tau P_{t} Y_{t} \\
T_{t}^{s}=\frac{1-\omega}{1-\chi} G_{t}+\tau P_{t} Y_{t}
\end{gathered}
$$

implying the government budget constraint

$$
(1-\chi) T_{t}^{s}+\chi T_{t}^{b}=G_{t}+\tau P_{t} Y_{t} .
$$

In particular, the parameter $\omega$, with $0<\omega<1$ determines who is paying for public spending. When $\omega=0$, they are the savers. When $\omega=1$, the borrowers while when $\omega=\chi$ all in equal shares. There are few changes to account for in our model, given the above specification, which are detailed in the Appendix. 

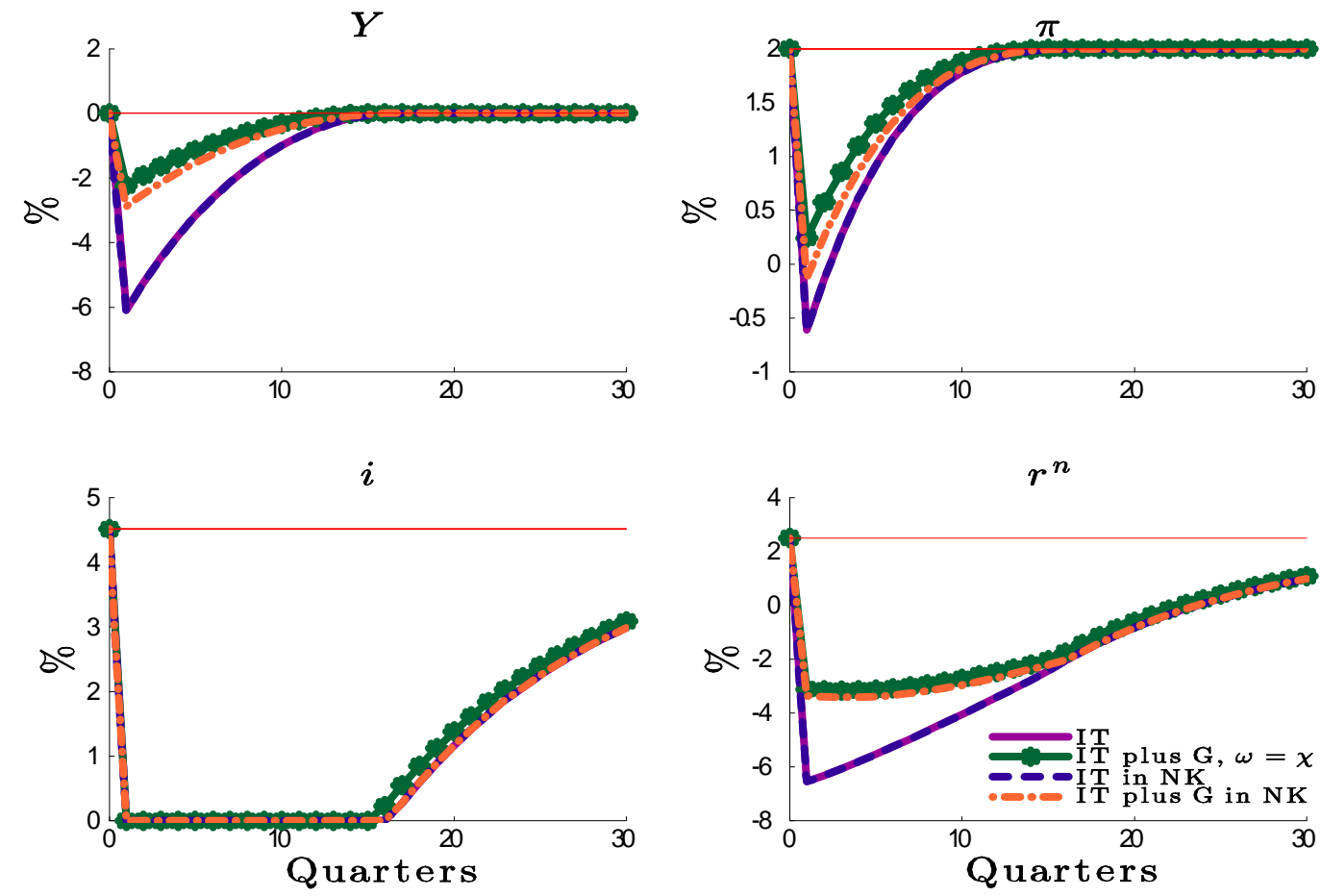

Figure 10: Comparison between the responses to a deleveraging shock with and without public spending. Line "IT": inflation-targeting policy in the model of this paper withouth public spending. Line "IT plus $\mathrm{G}, \omega=\chi$ ": inflation-targeting policy in the model of this paper with public spending and equal financing across agents $(\omega=\chi)$. Line "IT in NK": Inflationtargeting policy in the NK model without public spending. Line "IT plus G in NK": inflation-targeting policy in the NK model with public spending. (The responses of "IT" and "IT in NK" coincide by construction). Variables are: output $(Y)$, inflation rate $(\pi)$, nominal interest rate on savings $(i)$, natural rate of interest defined as in $(42)\left(r^{n}\right) . Y$ is in percentage deviation with respect to the steady state; $\pi, i$ and $r^{n}$ are in percent and at annual rates. 

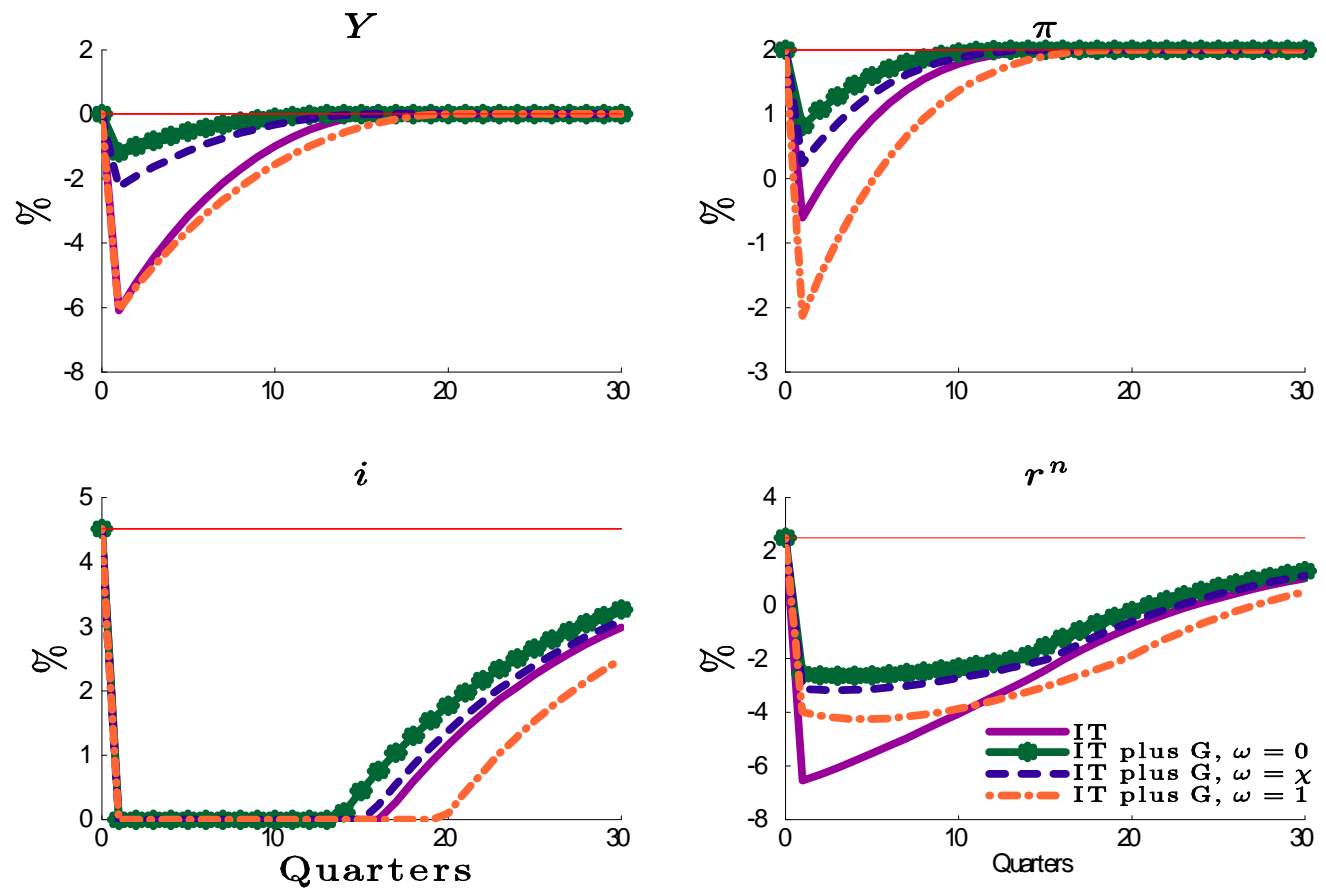

Figure 11: Comparison between the responses to a deleveraging shock with and without public spending. Line "IT": inflation-targeting policy in the model of this paper withouth public spending. Line "IT plus G, $(\omega=0)$ ": inflation-targeting policy in the model of this paper with public spending and financing all on savers $(\omega=0)$. Line "IT plus $\mathrm{G},(\omega=\chi)$ ": inflationtargeting policy in the model of this paper with public spending and equal financing across savers and borrowers savers $(\omega=\chi)$. Line "IT plus G, $(\omega=1)$ ": inflation-targeting policy in the model of this paper with public spending and financing all on borrowers $(\omega=1)$. Variables are: output $(Y)$, inflation rate $(\pi)$, nominal interest rate on savings $(i)$, natural rate of interest defined as in (42) $\left(r^{n}\right) . Y$ is in percentage deviation with respect to the steady state; $\pi, i$ and $r^{n}$ are in percent and at annual rates. 
We repeat the experiment of Section 6 where our model and the standard NK model are aligned in implying the same responses under inflation targeting assuming also the zero-lower bound. In this environment, we study the effects of an increase of government expenditure in both models. In particular we set $G_{t}=\psi Y_{t}$ and calibrate $\psi$, eventually with different values in the two models, in a way that the response of public spending in the first period is $3 \%$ in both models. Given this endogenous and same impulse of fiscal policy, Figure 10 shows the responses of output, inflation, nominal interest rate and the natural rate with and without public spending in the two models. In Figure 10, for the deleveraging model, we assume that public spending is financed equally across savers and borrowers, i.e. $\omega=\chi$. In Figure 11, we repeat the experiment for only the deleveraging model when $\omega=0, \chi$ or $1 .^{18}$

Looking at the first-period response of output, we see that in both models, by construction, output drops by $6.08 \%$. With a $3 \%$ increase in public spending in the first period, output drops by $2.24 \%$ in our model, when assuming that financing of public spending is equally shared across borrowers and savers $(\omega=\chi)$. This implies a first-period multiplier equal to 1.28 . In the standard New-Keynesian model, the drop in output with a $3 \%$ increase in public spending is $2.89 \%$ implying a multiplier of 1.06 . A model in which the dynamic of the natural rate of interest is endogenous to policy implies a different multiplier, and here even a larger multiplier. However, if considering a different redistribution of taxes in our model, we obtain a drop in output of only $1.18 \%$ if savers finance it all, with a larger multiplier of 1.63 . Instead, if taxes are levied on borrowers, output drops by more, $6.06 \%$, implying even a close-to-zero multiplier!

\section{Conclusions}

In this paper we have extended the standard New Keynesian model to take into account dynamic deleveraging. In doing so we provide a relatively general framework which we hope will be useful for further applications. We kept the analysis as simple as possible to provide a workhorse post-crisis model.

However, there are some obvious limitations to the analysis, essentially the price paid for the simplifications needed to keep the model tractable. The main one is the stylized assumption on the borrowing premium, which is in line with similar modelling devices used in the literature, like Curdia and

\footnotetext{
${ }^{18}$ It should be noted that the value of $\psi$ depends on the different assumptions on $\omega$.
} 
Woodford (2010, 2011). One contribution of our work is to generalize the fixed constraint of Eggertsson and Krugman (2012) to study dynamic and endogenous deleveraging. Along the direction of providing deeper microfoundations of financial frictions in New Keynesian models, De Fiore and Tristani (2012) analyze an agency cost model between banks and entrepreneurs. However, in their case, the financial friction acts on the aggregate-supply side as a cost-push shock and does not directly affect the natural rate of interest, unlike our framework.

We have also limited our focus to deleveraging shocks, but the analysis can be extended to study other sources of disturbances, like the more standard productivity and cost-push shocks, as well as pure financial disturbances not necessarily connected with deleveraging, such as credit and liquidity shocks.

Since we have emphasized the redistributive effects of policy between savers and borrowers, it would be natural to analyze other forms of debt, like long-term securities. Preliminary results in this direction show that the maturity structure of debt is irrelevant for the analysis of optimal monetary policy in our framework.

One main extension, as we see it, is to take the framework we develop and extend it into a medium scale DSGE model that can be estimated. We have chosen not to do so here, in order to obtain a tractable model that allows sharp analytic predictions about optimal policy and clearly generalizes the existing literature on the zero bound. We hope future research takes this analysis one step further into a fully estimated model along the lines recently pursued by Justiniano et al. (2014).

Finally, there could be many applications of the approach developed here to open economies or currency areas, to study the endogeneity of a country's deleveraging embedded in an international transmission mechanism. Benigno and Romei (2014) and Bhattarai et al. (2013) are examples in this direction.

\section{References}

[1] Adam, Klaus, and Roberto Billi (2006), "Optimal Monetary Policy under Commitment with a Zero Bound on Nominal Interest Rates," Journal of Money, Credit, and Banking 38(7), 1877-1905.

[2] Bhattarai, Saroy, Jae Won Lee and Woong Yong Park (2013), "Optimal Monetary Policy in a Currency Union with Interest Rate Spreads," 
mimeo, Penn State University.

[3] Benigno, Pierpaolo and Federica Romei (2014), " Debt Deleveraging and The Exchange Rate," Journal of International Economics, Vol. 93, pp. $1-16$.

[4] Christiano, Lawrence, Martin Eichenbaum, and Sergio Rebelo (2011), "When Is the Government Spending Multiplier Large?" Journal of Political Economy.119(1), 78-121

[5] Curdia, Vasco and Michael Woodford (2010), "Credit Spreads and Monetary Policy," Journal of Money Credit and Banking 42 (s1), 3-35.

[6] Curdia, Vasco and Michael Woodford (2011), "The Central-Bank Balance Sheet as an Instrument of Monetary Policy," Journal of Monetary Economics 58 (1), 54-79.

[7] De Fiore, Fiorella and Oreste Tristani (2012), "(Un)conventional Policy and The Zero Lower Bound," mimeo, ECB.

[8] Eggertsson, Gauti (2011), "What Fiscal Policy is Effective at Zero Interest Rates?" in D. Acemoglu and M. Woodford, eds., NBER Macroeconomics Annual 2010, Cambridge (US): MIT Press, Vol. 26, p. 59-112.

[9] Eggertsson, Gauti and Paul Krugman (2012), "Debt, Deleveraging and the Liquidity Trap: A Fisher-Minsky-Koo Approach," Quarterly Journal of Economics 127(3), 1469-1513.

[10] Eggertsson, Gauti, and Michael Woodford (2003), "The Zero Bound on Interest Rates and Optimal Monetary Policy," Brookings Papers on Economic Activity 1, 139-233.

[11] Galì, Jordi (2008). Monetary Policy, Inflation, and the Business Cycle: An Introduction to the New Keynesian Framework. Princeton University Press: Princeton.

[12] Geanakoplos John (2010), "The Leverage Cycle," in D. Acemoglu, K. Rogoff and M. Woodford, eds., NBER Macroeconomic Annual 2009, vol. 24: 1-65, University of Chicago Press.

[13] Guerrieri, Veronica and Guido Lorenzoni (2010), "Credit Crisis, Precautionary Savings and the Liquidity Trap," mimeo: MIT. 
[14] Hall, Robert E. (2011), "The Long Slump," American Economic Review 102, 431-469.

[15] Justiniano, Alejandro, Giorgio Primiceri and Andrea Tambalotti (2014), "Credit Supply and The Housing Boom," NBER working paper No. 18941.

[16] Krugman, Paul (1998), "It's Baaack! Japan's Slump and the Return of the Liquidity Trap," Brookings Papers on Economic Activity 2, 137-187.

[17] Mian, Atif, and Amir Sufi (2011), "House Prices, Home Equity-Based Borrowing, and the U.S. Household Leverage Crisis," American Economic Review 101, 2132-2156.

[18] Werning, Iván (2011), "Managing a Liquidity Trap: Monetary and Fiscal Policy," mimeo, MIT.

[19] Woodford, Michael (2003). Interest and Prices: Foundations of a Theory of Monetary Policy. Princeton University Press: Princeton. 


\section{A First-order conditions of optimal policy un- der commitment}

In this section, we characterize the optimal policy problem in details.

Optimal monetary policy under commitment minimizes the loss function

$$
L_{t_{0}}=\frac{1}{2} E_{t}\left\{\sum_{t=t_{0}}^{\infty} \beta^{t-t_{0}}\left[\hat{Y}_{t}^{2}+\chi(1-\chi) \lambda_{c}\left(\hat{C}_{t}^{b}-\hat{C}_{t}^{s}-c^{R}\right)^{2}+\lambda_{\pi}\left(\pi_{t}-\pi\right)^{2}\right]\right\}
$$

where $c^{R}$ captures the relative difference between the initial and final steadystate consumptions of borrowers and savers defined as $c^{R} \equiv\left[\left(C^{b}-\bar{C}^{b}\right)-\right.$ $\left.\left(C^{s}-\bar{C}^{s}\right)\right] / Y$. The minimization constrained by the following set of structural equations of the model:

$$
\begin{gathered}
\hat{Y}_{t}=\chi \hat{C}_{t}^{b}+(1-\chi) \hat{C}_{t}^{s} \quad\left(\lambda_{1}\right) \\
E_{t} \hat{C}_{t+1}^{b}-\hat{C}_{t}^{b}=\sigma\left[\hat{\imath}_{t}^{b}-E_{t}\left(\pi_{t+1}-\pi\right)+\lambda\left(\hat{b}_{t}-\hat{d}_{t}\right)\right] \quad\left(\lambda_{2}\right) \\
E_{t} \hat{C}_{t+1}^{s}-\hat{C}_{t}^{s}=\sigma\left[\hat{\imath}_{t}^{s}-E_{t}\left(\pi_{t+1}-\pi\right)\right] \quad\left(\lambda_{3}\right) \\
\hat{C}_{t}^{b}=\frac{\bar{b}}{(1+i)}\left(\hat{b}_{t}-\left(\hat{\imath}_{t}^{b}\right)\right)-\frac{\bar{b}}{\beta(1+i)}\left(\hat{b}_{t-1}-\left(\pi_{t}-\pi\right)\right)+\hat{Y}_{t} \quad\left(\lambda_{4}\right) \\
\hat{\imath}_{t}^{b}=\hat{\imath}_{t}^{s}+\varphi\left(\hat{b}_{t}-\hat{d}_{t}\right) \quad\left(\lambda_{5}\right) \\
\pi_{t}-\pi=\kappa \hat{Y}_{t}+\beta E_{t}\left(\pi_{t+1}-\pi\right) \quad\left(\lambda_{6}\right) \\
-\hat{\imath}_{t}^{s}+\hat{\imath}_{s s, t} \leq 0 . \quad\left(\lambda_{7}\right)
\end{gathered}
$$

Note that in each of the above equations we have written on the right the respective Lagrange multiplier.

First-order conditions of the optimal policy problem are:

$$
\begin{gathered}
\hat{Y}_{t}: \quad \hat{Y}_{t}+\lambda_{1, t}-\lambda_{4, t}-k \lambda_{6, t}=0 \\
\hat{C}_{t}^{s}: \quad-\left(\chi(1-\chi) \lambda_{c}\right)\left(\hat{C}_{t}^{b}-\hat{C}_{t}^{s}-\hat{C}_{t}^{R}\right)-(1-\chi) \lambda_{1, t}-\lambda_{3, t}+\frac{\lambda_{3, t-1}}{\beta}
\end{gathered}
$$




$$
\begin{gathered}
\hat{C}_{t}^{b}: \quad\left(\chi(1-\chi) \lambda_{c}\right)\left(\hat{C}_{t}^{b}-\hat{C}_{t}^{s}-\hat{C}_{t}^{R}\right)-(\chi) \lambda_{1, t}-\lambda_{2, t}+\frac{\lambda_{2, t-1}}{\beta}+\lambda_{4, t}=0 \\
\hat{\pi}_{t}: \quad \lambda_{\pi}\left(\pi_{t}-\pi\right)+\sigma \frac{\lambda_{2, t-1}}{\beta}+\sigma \frac{\lambda_{3, t-1}}{\beta}-\frac{\bar{b}}{(1+i) \beta} \lambda_{4, t}+\lambda_{6, t}-\lambda_{6, t-1}=0 \\
\hat{\imath}_{t}^{s}: \quad-\lambda_{3, t} \sigma-\lambda_{5, t}-\lambda_{7, t}=0 \\
\hat{\imath}_{t}^{b}: \quad-\lambda_{2, t} \sigma+\frac{\bar{b}}{(1+i)} \lambda_{4, t}+\lambda_{5, t}=0 \\
\hat{b}_{t}: \quad-\frac{\bar{b} .11}{(1+i)} \lambda_{4, t}+\frac{\bar{b}}{(1+i)} E_{t} \lambda_{4, t+1}-\phi \lambda_{5, t}-\sigma \lambda \lambda_{2, t}=0 \\
\lambda_{7, t}\left(-\hat{\imath}_{t}^{s}+\hat{\imath}_{s s, t}\right)=0 .
\end{gathered}
$$

The set of first-order conditions together with the equilibrium constraints is solved using a solution method which takes into account the zero lower bound (see also Eggertsson and Woodford, 2003).

\section{B Model with public expenditure}

In this section, we discuss in details the extension of Section 8 , in which we add public expenditure.

The steady state of consumption for borrowers and savers and output is now defined by the following equations

$$
\begin{gathered}
C^{s}=Y+\frac{(1-\beta)}{\Pi} \frac{\chi}{1-\chi} \bar{b}^{h i g h}-T^{s} \\
C^{b}=Y-\frac{(1-\beta)}{\Pi} \bar{b}^{h i g h}-T^{b} \\
\frac{Y^{\eta}}{z \exp (-z(Y-G))}=1,
\end{gathered}
$$

which can be written as

$$
\begin{gathered}
C^{s}=Y+\frac{(1-\beta)}{\Pi} \frac{\chi}{1-\chi} \tilde{b} Y-\frac{1-\omega}{1-\chi} s_{g} Y \\
C^{b}=Y-\frac{(1-\beta)}{\Pi} \tilde{b} Y-\frac{\omega}{\chi} s_{g} Y .
\end{gathered}
$$




$$
\frac{Y^{\eta}}{z \exp \left(-z\left(Y-s_{g} Y\right)\right)}=1
$$

where $s_{g}=G / Y, \tilde{b}=\bar{b}^{h i g h} / Y$.

We calibrate the share of public spending over GDP at $s_{g}=0.3$. Given the other parameters of Table 1, we can compute the steady-state of the model.

In a log-linear approximation around the steady state, the model can be written through the following set of equations

$$
\begin{gathered}
E_{t} \hat{C}_{t+1}^{b}=\hat{C}_{t}^{b}+\sigma\left[\hat{\imath}_{t}^{b}-E_{t}\left(\pi_{t}-\pi\right)+\lambda\left(\hat{b}_{t}-\hat{d}_{t}\right)\right] \\
E_{t} \hat{C}_{t+1}^{s}=\hat{C}_{t}^{s}+\sigma\left(\hat{\imath}_{t}-E_{t} \hat{\pi}_{t+1}\right) \\
\hat{\imath}_{t}^{b}=\hat{\imath}_{t}+\phi\left(\hat{b}_{t}-\hat{d}_{t}\right) \\
\hat{Y}_{t}=\chi \hat{C}_{t}^{b}+(1-\chi) \hat{C}_{t}^{s}+g_{t} \\
\hat{C}_{t}^{b}=\frac{\bar{b}}{1+i}\left(\hat{b}_{t}-\hat{\imath}_{t}^{b}\right)-\frac{\bar{b}}{\beta(1+i)}\left(\hat{b}_{t-1}-\left(\pi_{t}-\pi\right)\right)+\hat{Y}_{t}-\hat{t}_{t}^{b} \\
\pi_{t}-\pi=\kappa\left(\hat{Y}_{t}-\frac{\sigma^{-1}}{\sigma^{-1}+\eta} g_{t}\right)+\beta E_{t}\left(\pi_{t+1}-\pi\right)
\end{gathered}
$$

where

$$
\begin{gathered}
g_{t}=\hat{t}_{t} \\
\hat{t}_{t}^{b}=\frac{\omega}{\chi} \hat{t}_{t} \\
\hat{t}_{t}^{s}=\frac{1-\omega}{1-\chi} \hat{t}_{t}
\end{gathered}
$$

and we have further defined the following variables

$$
g_{t}=\frac{\left(G_{t}-G\right)}{Y} \quad \hat{t}_{t}=\frac{T_{t}-T}{Y} .
$$

Note that the parameter $\omega$ is between 0 and 1 . When $\omega=0$, the burden of public-spending financing is on the savers. When $\omega=1$ all the financing is on borrowers while when $\omega=\chi$ is uniform across agents.

In Figures (10) and (11), first we compute the natural rate of interest in the deleveraging model under inflation targeting and assuming that $g_{t}=0$. This is given by

$$
r_{t}^{n}=-\chi(\varphi+\lambda)\left(\hat{b}_{t}-\hat{d}_{t}\right)
$$


We then input the same $r_{t}^{n}$ in the following NK model with public spending

$$
\begin{gathered}
\left(\pi_{t+1}-\pi\right)=\kappa\left(\hat{Y}_{t}-\frac{\sigma^{-1}}{\sigma^{-1}+\eta} g_{t}\right)+\beta E_{t}\left(\pi_{t+1}-\pi\right) \\
\hat{Y}_{t+1}-g_{t+1}=\hat{Y}_{t}-g_{t}+\sigma\left[\hat{\imath}_{t}-E_{t} \pi_{t+1}-r_{t}^{n}\right]
\end{gathered}
$$

Given $g_{t}=0$, the inflation-targeting policy of our model under zero-lower bound is equivalent to the inflation-targeting in the NK model under zerolower bound, for the path of inflation, output and nominal interest rate. This is shown in Figure (10) with the lines IT and IT in NK.

We then assume the following process for $g_{t}$

$$
g_{t}=-\psi \hat{Y}_{t}
$$

and consider a deleveraging shock of the same magnitude as before, again in the case in which the central bank targets inflation and hits the zero bound. Considering the same deleveraging shock and same $r_{t}^{n}$ computed above, we set the parameter $\psi$ in both models in such a way that the initial response of $g_{t}$ is $3 \%$ in the first period in both models. This means eventually that $\psi$ is chosen in a different way in both models. In particular we repeat this experiment for the three different cases, i.e. when $\omega=0, \chi, 1$, in the deleveraging model, implying therefore different choices of $\psi$.

Finally, it should be noted that when $g_{t} \neq 0$ the natural rate of interest is computed as

$$
\tilde{r}_{t}^{n}=-\chi(\varphi+\lambda)\left(\hat{b}_{t}-\hat{d}_{t}\right)-\sigma^{-1}\left(E_{t} g_{t+1}-g_{t}\right)
$$

in the deleveraging model while is given by

$$
r_{t}^{\prime n}=r_{t}^{n}-\sigma^{-1}\left(E_{t} g_{t+1}-g_{t}\right)
$$

in the NK model. 